\title{
Zika virus-specific IgM elicited during pregnancy exhibits ultrapotent neutralization
}

2 Tulika Singh ${ }^{1,2}$, Kwan-Ki Hwang ${ }^{1, \S}$, Andrew S. Miller ${ }^{3}$, Rebecca L. Jones ${ }^{1}$, Cesar A. Lopez ${ }^{4}$ 3 Camila Giuberti ${ }^{5}$, Morgan A. Gladden ${ }^{1}$, Itzayana Miller ${ }^{1,6}$, Helen S. Webster ${ }^{1}$, Joshua A. 4 Eudailey ${ }^{1,6}$, Kan Luo ${ }^{1}$, Tarra Von Holle ${ }^{1}$, Robert J. Edwards ${ }^{1}$, Sarah Valencia ${ }^{1}$, Katherine E. 5 Burgomaster ${ }^{7}$, Summer Zhang ${ }^{8}$, Jesse F. Mangold ${ }^{1, \dagger}$, Joshua J. Tu ${ }^{1}$, Maria Dennis ${ }^{1}$, S. Munir 6 Alam $^{1}$, Lakshmanane Premkumar ${ }^{4}$, Reynaldo Dietze ${ }^{5,9}$, Theodore C. Pierson ${ }^{7}$, Eng Eong Ooi ${ }^{8}$, 7 Helen M. Lazear ${ }^{4}$, Richard J. Kuhn ${ }^{3}$, Sallie R. Permar ${ }^{1,6 *}$, Mattia Bonsignori ${ }^{1,10 *}$

$9{ }^{1}$ Duke Human Vaccine Institute, Duke University School of Medicine, Durham, NC 27710, USA

10 'Division of Infectious Diseases and Vaccinology, School of Public Health, University of California, 11 Berkeley, Berkeley, CA 94709, USA.

$12{ }^{3}$ Department of Biological Sciences, Purdue Institute of Inflammation, Immunology, and Infectious 13 Disease, Purdue University, West Lafayette, IN 47907, USA

$14{ }^{4}$ Department of Microbiology and Immunology, University of North Carolina at Chapel Hill, Chapel 15 Hill, NC 27599, USA

${ }^{5}$ Núcleo de Doenças Infecciosas, Universidade Federal do Espírito Santo, Vitoria, Espírito Santo 29075-910, Brazil

${ }^{6}$ Department of Pediatrics, Weill Cornell Medicine, New York City, NY 10065, USA

${ }^{7}$ Viral Pathogenesis Section, Laboratory of Viral Diseases, National Institute of Allergy and Infectious

Diseases, National Institutes of Health, Bethesda, MD 20892 USA.

$21{ }^{8}$ Duke-National University of Singapore Medical School, 169857, Singapore

${ }^{9}$ Global Health \& Tropical Medicine, Instituto de Higiene e Medicina Tropical, Universidade Nova de Lisboa, Lisbon 1349-008, Portugal

${ }^{10}$ Translational Immunobiology Unit, Laboratory of Infectious Diseases, National Institute of Allergy and Infectious Diseases, National Institutes of Health, Bethesda, MD 20892, USA

$\S$ Current address: 124 Cosgrove Ave, Chapel Hill, NC 27514, USA

27 † Current address: Department of Microbiology, Icahn School of Medicine, New York City, NY 28 10029-6574, USA 
bioRxiv preprint doi: https://doi.org/10.1101/2021.11.23.469700; this version posted November 24, 2021. The copyright holder for this preprint (which was not certified by peer review) is the author/funder, who has granted bioRxiv a license to display the preprint in perpetuity. It is made available under aCC-BY 4.0 International license.

\section{Key points}

33 1. Plasma IgM contributes to early ZIKV neutralization during pregnancy

34 2. Ultrapotent neutralization by pentameric $\mathrm{DH} 1017 . \lg \mathrm{M}$ mAb depends on isotype

35 3. DH1017.IgM can engage all binding sites concurrently through different angles of approach 4. $\mathrm{DH} 1017 . \mathrm{lgM}$ protects mice against lethal ZIKV challenge 


\section{Summary}

38 Congenital Zika virus (ZIKV) infection results in neurodevelopmental deficits in up to $14 \%$ of

39 infants born to ZIKV-infected mothers. Neutralizing antibodies are a critical component of 40 protective immunity. Here, we demonstrate that plasma IgM responses contribute to ZIKV 41 immunity in pregnancy, mediating neutralization up to three months post symptoms. From a ZIKV-

42 infected pregnant woman, we established a B cell line secreting a pentameric ZIKV-specific IgM 43 (DH1017.lgM) that exhibited ultrapotent ZIKV neutralization dependent on the IgM isotype.

44 DH1017.IgM targets a novel envelope dimer epitope within Domain II. The arrangement of this 45 epitope on the virion is compatible with concurrent engagement of all ten antigen-binding sites of $46 \mathrm{DH} 1017 . \mathrm{IgM}$, a solution not achievable by IgG antibodies. DH1017.IgM protected against lethal 47 ZIKV challenge in mice. Our findings identify a unique role of antibodies of the IgM isotype in 48 protection against ZIKV and posit DH1017.IgM as a safe and effective candidate 49 immunoprophylactic, particularly during pregnancy. 


\section{Introduction}

Zika virus (ZIKV) emergence in the Americas revealed it to be congenitally transmitted, causing microcephaly and other birth defects in up to $14 \%$ of infants born to ZIKV-infected pregnancies (Reynolds et al., 2017). Even infants born seemingly healthy following maternal ZIKV infection may develop neurodevelopmental defects years later (Nielsen-Saines et al., 2019). As ZIKV mostly results in mild febrile disease in healthy adults, its greatest disease burden arises through infections in pregnancy. In the 2015-2016 epidemic, ZIKV re-emergence in a susceptible population led to 11,000 cases of microcephaly in Brazil alone (Campos et al., 2018). There is no licensed vaccine for ZIKV, and the vaccine development and testing pipeline has stalled due to limited ZIKV circulation (Morabito and Graham, 2017).

Protective immunity in pregnancy could prevent ZIKV infection, congenital transmission, and lifelong congenital Zika syndrome sequelae. Neutralizing antibodies (nAbs) have been shown to be a critical aspect of protective immune responses against ZIKV and other flavivirus infections (Abbink et al., 2016; Hombach et al., 2005; Katzelnick et al., 2017; Kreil et al., 1997; Kwek et al., 2018; Larocca et al., 2016; Mason et al., 1973; Richner et al., 2017), yet nAb studies have largely focused on IgG antibodies. However, flavivirus infections are also characterized by virus-specific and prolonged IgM responses. IgM are pentameric molecules with 5-times as many potential antigen binding sites compared to IgG. Conventionally, IgM are thought of as early, short-lived, and low-affinity antibodies that are not somatically matured and thus unable to confer potent viral neutralization. Yet, early neutralizing IgM responses have been identified for other flaviviruses such as West Nile virus and yellow fever virus (Diamond et al., 2003; Gasser et al., 2020; Monath, 1971; Wec et al., 2020). A common feature is that these viruses present dense and repetitive structures on their surface, which may favor avid multivalent interactions with $B$ cell receptors and influence the functional antibody profile via B cell stimulation and clonal selection. Interestingly, long-lasting ZIKV-reactive IgM responses have recently been independently identified in two distinct populations (Griffin et al., 2019; Stone et al., 2020). The presence of ZIKV-specific IgM lasting up to multiple years, when the typical half-life of IgM is 5 days, suggests that ZIKV-reactive IgM expressing B cells are specifically activated and expanded upon ZIKV infection (Lobo et al., 2004). While neutralizing activity is primarily attributed to IgG isotype antibodies, IgM may have an underappreciated role in ZIKV immunity.

The role of ZIKV IgM and IgM-producing B cells is especially understudied in pregnancy, a period of differential immunomodulation where ZIKV infections lead to their greatest disease burden. Early in pregnancy $B$ cells are stimulated to produce IL-10, and subsequently B cell lymphopoiesis is suppressed, which promotes survival of mature $B$ cells and decreases circulating naive $B$ cell frequency (Christiansen et al., 1976; Lima et al., 2016; Nguyen et al., 2013). Retention of the IgM isotype diminishes as B cells differentiate from naïve to memory and antibody-secreting cells, which shapes $B$ cell clonal selection in response to infection and long-lasting protective immunity (King et al., 2021). These factors may impact the magnitude and quality of ZIKV-specific IgM and IgG immunity in pregnancy.

In this study, we sought to define the kinetics and role of IgM in the control of ZIKV infection during pregnancy. We evaluated the contribution of plasma IgM to ZIKV neutralization in pregnant 
women over time and demonstrated that, in pregnancy, plasma IgM contributes to ZIKV neutralization primarily within the first 3 months of infection, regardless of prior exposure to other flaviviruses. We probed the $B$ cell repertoire from peripheral blood of mothers with primary and secondary ZIKV infections and established 9 ZIKV-binding B lymphoblastoid cell lines (B-LCL). One of them produced an IgM antibody, DH1017.IgM, in its native pentameric conformation. DH1017.IgM was somatically mutated, did not cross-react with other flaviviruses, and displayed ultrapotent ZIKV neutralization that depended on its isotype. Structural studies identified a mode of antigen recognition on the ZIKV virion surface compatible with the concurrent engagement of all ten antigen-binding sites, a solution that is not available to antibodies of the lgG isotype, which have only two antigen-binding sites. The ultrapotent activity and protection mediated by $\mathrm{DH} 1017 . \mathrm{IgM}$ in mice suggest that $\mathrm{DH} 1017 . \mathrm{IgM}$ is a candidate for anti-ZIKV immunoprophylaxis.

\section{Results}

\section{IgM contributes to plasma ZIKV neutralization during early phases of infection in pregnant} women.

We previously described a cohort of pregnant women from the 2015-2016 ZIKV outbreak in Brazil who presented with ZIKV-like symptoms of fever and/or rash in pregnancy and were serologically confirmed for ZIKV infection (Singh et al., 2019). Serologic evidence of prior exposure to DENV was demonstrated in most ZIKV-infected mothers in the cohort, and termed secondary ZIKV (Singh et al., 2019). Both primary (P24 and P54) and secondary (P14, P15, P17, P19, P23, P50, P56 and P73) ZIKV infection cases were included in this study. Among them, eight women were diagnosed during acute infection by serum PCR and two were identified as ZIKV-exposed based on ZIKV and DENV 1-4 neutralization titers (Singh et al., 2019). From 9 subjects, pregnancy and delivery plasma samples were available between 8- and 406-days post-symptoms (DPS). From 1 subject (P73), multiple longitudinal samples were collected between 8-406 DPS. Subject P73 developed prolonged viremia (up to 42 DPS), while all other subjects were viremic only up to their first visit (Singh et al., 2019). All subjects had high levels of ZIKV-neutralizing plasma antibodies at delivery (median FRNT $50=4566$; range: 650-14,959) (Singh et al., 2019).

To evaluate the contribution of plasma IgM to ZIKV neutralization during pregnancy, we measured total IgM and IgG concentrations, ZIKV binding IgG, and ZIKV neutralization of paired samples after mock and IgM depletion (Table S1). Subject P73 displayed the highest IgM-mediated ZIKV plasma neutralization, which started modestly at 8 DPS (7\%), then rapidly peaked to $78 \%$ at 14 DPS ranging from $3 \%$ to $52 \%$ up to 112 DPS following a multimodal distribution and waned thereafter to undetectable levels. (Figure 1). An important contribution of IgM to plasma ZIKV neutralization was confirmed across all the samples collected between 14 and 100 DPS from each of the other subjects (range: 17-49\%), regardless of serostatus (i.e., primary or secondary ZIKV infection). IgM plasma contribution was minimal to null in samples collected during late infection (range: $0-4 \%$ ), except for subject P23, who displayed $28 \%$ of IgM-mediated ZIKV neutralization at 209 DPS. Overall, $90 \%(9 / 10)$ of plasma samples collected within 3 months of symptomatic infection from 4 mothers demonstrated $>10 \%$ IgM-attributable ZIKV neutralization, but only $18 \%(2 / 11)$ of samples from beyond 3 months demonstrated this response (Figure 1). 


\section{Isolation of ZIKV-specific, ultrapotent neutralizing mAb DH1017.IgM.}

We next probed the B cell compartment of subject P73 at 28 and 71 DPS to identify B cells producing ZIKV-neutralizing IgM. We also selected four ZIKV-infected pregnant women from the same cohort (Singh et al., 2019), including one woman with primary ZIKV infection (P54: 29 and 77 DPS) and three women with secondary ZIKV infection (P34 at 162 DPS, P56 at 19 DPS, and P73 at 28 and 71 DPS) for a comparative analysis of the ZIKV-specific B cell repertoire. We enriched for ZIKV-reactive B cells by sorting either unfractionated or memory B cells (MBCs) using a fluorescent ZIKV virion as bait and cultured cells at limiting dilution to derive human B-LCL through EBV transformation as described (Bonsignori et al., 2011, 2018).

Across subjects, ZIKV-reactive B cells constituted $0.6-1.7 \%$ of the circulating unfractionated $B$ cell pool (Figure S1A). Regardless of serostatus and time of sample collection relative to symptoms onset, the frequency of ZIKV-reactive MBCs out of total MBCs was uniformly higher than the ZIKV-reactive B cells out of the total unfractionated B cell pool $(0.7-2.6 \%$ vs $0.6-1.7 \%$; $p<0.03$, paired t-test) (Figure S1A). On average, ZIKV-reactive memory B cells comprised $52 \%$ of total ZIKV-reactive B cells with higher frequencies observed in secondary infections (P73, P56, P34) than in the primary ZIKV infection case (P54) (46-69\% vs 34\%; Figure S1B), compatible with a re-engagement of pre-existing cross-reactive memory $B$ cells in secondary infection.

In vitro B cell stimulation across all 4 subjects yielded a total of 97 lg-secreting culture supernatants, of which 37 were from unfractionated B cells and 60 from memory B cells. Among unfractionated cultures, 13 cultures contained both IgG and IgM, whereas all cultures from memory B cells were of a single Ig isotype. Ig concentrations ranged from 3 to $>3000 \mathrm{ng} / \mathrm{ml}$ with a geometric mean of $146 \mathrm{ng} / \mathrm{ml}$. Overall, 49 of $97(50.5 \%)$ lg-secreting culture supernatants confirmed ZIKV reactivity: 17 (15 IgG and $2 \mathrm{lgM}$ ) from unfractionated B cells and 32 (all IgG) from memory B cell cultures (Figure S1C). From ZIKV-reactive Ig-secreting cultures, we established 9 B-LCL, 8 of which produced IgG monoclonal antibodies (mAbs) and one, termed DH1017.IgM, produced an IgM mAb.

Analysis of the $\lg \mathrm{V}(\mathrm{D}) \mathrm{J}$ rearrangement immunogenetics demonstrated that none of the B-LCLs were clonally related (Table 1). Diverse heavy chain variable gene segments were used and paired with either $\kappa$ or $\lambda$ light chains $\left(V_{L}\right)$, without $V_{H} / V_{L}$ pairing preferences. CDRH3 lengths ranged between 12 and 22 amino acids (median: 15 amino acids). Overall, $V_{H}$ and $V_{L}$ somatic hypermutation (SHM) frequency ranged from $3.1 \%$ to $10.8 \%$, and $1.5 \%$ to $8.0 \%$, respectively (Table 1). The $\mathrm{V}_{\mathrm{H}} \mathrm{SHM}$ frequency of sequences obtained from unfractionated $\mathrm{B}$ cells and memory $B$ cells was statistically similar ( $p>0.05$, Kolmogorov-Smirnov test). DH1017. IgM used the $V_{H} 4-31$ gene segment paired with $V_{\lambda} 1-51$ and had a 15 amino acid-long CDRH3 (Table 1). While the B cell that expressed $\mathrm{DH} 1017 . \mathrm{IgM}$ was isolated from unfractionated $\mathrm{B}$ cells and we could not determine its origin from the naïve or memory B cell compartment, the SHM frequency in the $\mathrm{DH}$ 1017. IgM V(D)J rearrangements were within the range of other IgG $\mathrm{mAbs}$ that we isolated (3.8\% for the heavy chain and $3.4 \%$ for the light chain) with 7 nucleotide mutations in the $V_{H}$ and 9 in the $V_{L}$. All but two of these nucleotide changes were substitution mutations. Nine of the 16 nucleotide substitutions (56\%) occurred in canonical activation-induced cytidine deaminase (AID) 
hotspot motifs with high mutability rates (Yaari et al., 2013). The remaining 7 substitutions occurred in neutral or cold-spot motifs (Table S2).

MAbs were produced and purified from the $9 \mathrm{~B}-\mathrm{LCLs}$ for functional characterization. In a native gel, mAb DH1017.IgM yielded two bands at $\sim 970 \mathrm{kDa}$ and $\sim 1048 \mathrm{KDa}$ (Figure 2A), which is compatible with pentameric and hexameric IgM isoforms (Keyt et al., 2020; Wiersma et al., 1998). Negative stain electron microscopy class average analysis supported the presence of both pentameric and hexameric isoforms, with hexamers representing $18 \%$ and pentamers representing $73 \%$ of all observed images (Figure $\mathbf{2 A}$ ).

All purified mAbs confirmed binding to ZIKV. While 126-1-D11.IgG bound weakly even at high concentrations ( $\log A \cup C=2.0$ ), all other mAbs bound with LogAUC ranging from 2.7 to 5.9, with the strongest ZIKV-binding mAb being DH1017.IgM (Figure 2B). Since plasma antibody displayed substantial cross-reactivity with DENV in all subjects except primary infection subject P54 (Figure S2A), we determined cross-reactivity of the nine mAbs with DENV 1-4 strains. Based on their binding profile, the mAbs segregated into two clusters (Figure 2C). Cluster I comprised mAbs 123-3-G2.IgG, 124-4-C8.lgG, 124-1-C2.lgG, and 124-2-G3.lgG that bound to one or more DENV 1-4 strains better than to ZIKV. These mAbs were isolated from memory B cells of mothers with secondary ZIKV-infection (P73 and P56), which parallels the plasma cross-reactivity profile and further implies re-engagement of pre-existing DENV-reactive memory B cells. Conversely, cluster II mAbs bound more strongly to ZIKV than to DENV, for which cross-reactivity was either at or below limit of detection, which suggests that these mAbs may constitute a de novo immune response to ZIKV. Notably, DH1017.IgM did not cross-react with or neutralize any of the four DENV serotypes (Figure 2C and Figure S2B).

Five of the nine ZIKV-specific mAbs mediated neutralization of the ZIKV PRVABC59 strain (Figure 2D). Mab 124-4-C8.IgG neutralized weakly with FRNT Fo $>10 \mu \mathrm{M}$. Mabs 119-1-D7.lgG, 119-5-C5.IgG and 119-4-D6.IgG neutralized with $\mathrm{FRNT}_{50}=5.8 \mathrm{nM}, 9.2 \mathrm{nM}$ and $9.7 \mathrm{nM}$, respectively. Remarkably, DH1017. IgM neutralized ZIKV with $\sim 500$ - to 1000-fold higher potency (FRNT ${ }_{50}=12 \mathrm{pM}$ ) (Figure 2D). DH1017.IgM neutralization of the ZIKV PRVABC59 strain was repeated multiple times $(n=10)$ and potent neutralization was independently confirmed by multiple operators (geometric mean [GM] FRNT 50 : 12 pM; range: 4-31 pM). DH1017.IgM also neutralized the ZIKV H/PF/2013 strain with comparable potency (GM FRNT 50 : 14 pM; range: 8-26 pM) (Figure S2C). We compared DH1017.IgM potency with a panel of well characterized ZIKV-neutralizing IgG mAbs: EDE1 C8, EDE1 C10, ZIKV-893, rZIKV-195, G9E, ZV-2, ZIKV-752, ZKA190, and HuZV-67 (Collins et al., 2019; Gilchuk et al., 2020; Hasan et al., 2017a; Long et al., 2019; Rouvinski et al., 2015; Sapparapu et al., 2016; Wang et al., 2017; Zhao et al., 2016). In this sideby-side comparison, DH1017.IgM neutralized more potently than all other IgG ZIKV neutralizing $\mathrm{mAbs}$ in the panel (FRNT 50 range: $95 \mathrm{pM}-15.5 \mathrm{nM}$ ) (Figure 2E). Neutralizing antibodies of the $\operatorname{lgG}$ isotype with $\mathrm{IC}_{50}<10 \mathrm{ng} / \mathrm{ml}$, i.e. $66.7 \mathrm{pM}$, are defined as ultrapotent (Smith et al., 2015). Hence, $\mathrm{DH} 1017$. IgM meets the definition of ultrapotent ZIKV-neutralizing antibody. 


\section{Impact of isotype on DH1017.IgM functions.}

We recombinantly produced the Fab and IgG1 isoforms (DH1017.Fab and DH1017.IgG) and measured binding to ZIKV H/PF/2013 envelope (E) protein monomer and dimer. DH1017.lgM bound more potently than DH1017.IgG and DH1017.Fab to ZIKV E monomer $\left(E_{50}=202 \mathrm{pM}\right.$, $463 \mathrm{pM}$ and $1.24 \mathrm{nM}$, respectively) (Figure 3A). The difference in binding potency among the different isotypes was more profound for the ZIKV E dimer: DH1017.IgM EC $E_{50}=91 \mathrm{pM}$, DH1017.lgG $\mathrm{EC}_{50}=929 \mathrm{pM}$, and DH1017.Fab $\mathrm{EC}_{50}=25.1 \mathrm{nM}$ (Figure 3B). To test the contribution of the $\mathrm{Fc}$ region of $\mathrm{DH} 1017 . \mathrm{IgM}$ to its increased level of binding, we compared the DH1017.IgM and DH1017.IgG binding kinetics to ZIKV E dimer using a BLI format with immobilized mAb. Under these conditions, DH1017.IgM and DH1017.IgG displayed similar dissociation kinetic ( $k_{\text {off }}=1.03$ and $0.91 \mathrm{~s}^{-1} \times 10^{-2}$, respectively) and affinity $\left(K_{d}=106\right.$ and $123 \mathrm{nM}$, respectively). This suggests that the $\mu$-chain $\mathrm{Fc}$ of $\mathrm{DH} 1017 . \operatorname{lgM}$ does not contribute towards its affinity for $E$ protein.

We then assessed the ability of DH1017.IgM, DH1017.IgG and DH1017.Fab to bind to whole Zika PRVABC59 virion. DH1017.Fab only interacted weakly with ZIKV $\left(E_{50}>2 \mathrm{mM}\right)$ whereas $\mathrm{DH} 1017$.lgG bound strongly $\left(\mathrm{EC}_{50}=112 \mathrm{pM}\right)$, and $\mathrm{DH} 1017 . \mathrm{lgM}$ bound 5-fold more potently than DH1017.IgG $\left(E_{50}=22 \mathrm{pM}\right)$ (Figure 3C). Remarkably, the functional difference between $\mathrm{DH}$ 1017.IgM, DH1017.IgG and DH1017.Fab was even greater for ZIKV neutralization. $\mathrm{DH}$ 1017.IgM neutralization potency $\left(\mathrm{FRNT}_{50}=9 \mathrm{pM}\right)$ was $>40$-fold higher than $\mathrm{DH} 1017 . \lg$ $\left(\mathrm{FRNT}_{50}=366 \mathrm{pM}\right.$; Figure 3D), whereas DH1017.Fab yielded a shallow neutralization curve $\left(\mathrm{FRNT}_{50}=93 \mathrm{nM}\right)$ with 10,000-fold worse potency than DH1017.lgM (Figure 3D). These data demonstrate that $\mathrm{DH} 1017 . \mathrm{IgM}$ increased binding and ultrapotent neutralization depended on the $\lg \mathrm{M}$ isotype.

Since antibody-mediated complement deposition can reduce the amount of mAb required to neutralize virus, we tested the effect of complement from normal human serum (NHS) on DH1017.IgG and DH1017.lgM neutralizing activities. Exogenous human complement from NHS enhanced ZIKV neutralization potency of both mAbs in a dose-dependent manner (Figure 3E). At all doses of NHS tested (5-25\% v/v), DH1017.lgM retained more potent neutralizing activity compared to DH1017.lgG. The largest improvement in neutralization potency was observed in the 25\% NHS condition with 4.3-fold and 3.7-fold increase in potency for DH1017.IgM and $\mathrm{DH} 1017 . \mathrm{lgG}$, respectively (Figure 3E). These data demonstrate that neutralization potency of the $\mathrm{DH} 1017 \mathrm{mAb}$ in its IgG and IgM isoforms is enhanced in presence of complement.

Sub-neutralizing concentrations of flavivirus neutralizing IgG can mediate antibody-dependent enhancement (ADE) of viral infection through interactions of immune complexes with plasma membrane-anchored FcyR, particularly on monocytes (Chan et al., 2015; Halstead, 1988; Halstead and O'Rourke, 1977). DH1017.IgG mediated ADE in both K562 and THP-1 cells whereas DH1017. IgM did not (Figures 3F, G). DH1017.IgM also did not mediate ADE in THP$1.2 S$ cells, a subclone of THP-1 cells with increased sensitivity to ADE (Chan et al., 2014) (Figure 3H). Similarly, DH1017.IgM did not mediate ADE in primary monocytes (Figure S3A). Finally, to further characterize the safety profile of DH1017.IgM, DH1017.IgG and DH1017.Fab, we measured binding to nine autoantigens associated with autoimmune diseases. All isotypes tested 
negative for all antigens (Figure S3B). Further, they did not demonstrate intracellular immunofluorescent staining of Hep-2 cells (Figure S3C).

\section{Structural characterization of the epitope of the DH1017 clone on the Zika virion}

Using cryo-electron microscopy (cryo-EM) and single particle reconstruction, we identified a set of 4104 ZIKV H/PF/2013 particles bound with DH1017.Fab and generated a cryo-EM density map. A surface shaded view of the virus-Fab complex is shown in Figure 4A and demonstrates the sites of Fab binding to the surface of the particle. The cryo-EM density map resolution is 5.3 $\AA$ as determined from the Fourier Shell Correlation co-efficient 0.143 (Figure S4A).The $C_{\alpha}$ backbone of the E glycoprotein ectodomains from the ZIKV asymmetric unit (PDB 6CO8; Sevvana et al., 2018) is composed of three $E$ monomers, chains $A, C$, and $E$ (Figure 4B). Their position in the density map is shown in Figure S4B. In this asymmetric unit, Chain A lies alongside the antiparallel homodimer formed by chains $C$ and $E$ (Figure 4B). The fitted asymmetric unit is repeated 60 times within the density map demonstrating icosahedral symmetry like previous Zika virus structures (Sevvana et al., 2018; Sirohi et al., 2016).

The $\mathrm{C}_{\alpha}$ backbone of the homology model of the DH1017.Fab was fit into the cryo-EM density map (Figure S4B). It shows that the $\mathrm{DH} 1017$ variable domain interacts primarily with DIl of all three $\mathrm{E}$ monomers in the asymmetric unit, and at the interface of DII and DI on chains A and $C$ (Figure 4B, S4B). The DH1017.Fab epitope footprint was defined by residues of the $E$ ectodomain glycoprotein on the surface of the virus within $6 \AA$ from the $\mathrm{C}_{\alpha}$ backbone of the $\mathrm{DH} 1017$ variable domain structure (Table S3, Figure 4B, C, D). The DH1017.Fab paratope footprint was defined by Fab residues within $6 \AA$ from the $C_{\alpha}$ backbone of the $E$ ectodomain glycoprotein of the virus surface and included all three heavy chain CDRs and FRH3 (Table S3).

There are two 2-fold axes of symmetry on the virus surface: the icosahedral 2-fold (i2f) axis delineates symmetry at the juncture of two antiparallel asymmetric units on the repetitive virion surface between $A$ and A', whereas the quasi 2-fold (q2f) axis describes symmetry within the antiparallel $E$ dimer between chains $C$ and $E$ (Figure 4C). Each asymmetric unit contains two epitope footprints, at the i2f and q2f symmetry axes, respectively (Figure 4C). At the i2f axis one half of the epitope footprint is located on chain A' and the other half of on chain A (Figure 4C), whereas at the q2f axis, most epitope residues are on chain $C$, with some on chain $E$. (Figure 4C, S4B). At the i2f axis, one bound Fab will exclude the other i2f site related by two-fold symmetry from being bound. Whereas, at the q2f axis, the position on chain $C$ and $E$ is fully occupied. The result is an occupancy of 1.5 Fab per asymmetric unit.

Cryo-EM density data at the q2f axis identified as the Fab constant and variable domains occupied a single position (Figure 4A). However, two distinct positions of Fab constant domain densities could be identified at the i2f axis (Figure 4A, S4B). Hence, at the i2f axis the epitope can be approached from two angles but at the q2f it is only approached at one angle. At the i2f axis, only one apparent position for variable domain density was identified. It is most likely an average of two distinct variable domains bound to the virus surface at different constant domain angles (Figure S4B). 
A top-down view of the virus particle shows that Fab densities at the $q 2 f$ and $i 2 f$ axes form a ring around the 5-fold axis of symmetry (i5f) with the constant domains pointing toward the i5f axis (Figure S4C). Computational modeling of the DH1017.IgM pentamer (PDB 2CRJ) above the surface of the virion suggests the Fc domain can be centered and positioned above the i5f axis with the $\mathrm{C} \mu 3$ ends above the constant domains of the Fabs (Figure 5A). The IgM $\mathrm{C} \mu 2$ domains are flexible and can bend up to 90 degrees relative to the planar $\mathrm{C} \mu 4-\mathrm{C} \mu 3-\mathrm{J}$ portion, facilitating a bent, umbrella-like, IgM conformation (Keyt et al., 2020; Murphy et al., 2012; Sharp et al., 2019). The flexibility at $\mathrm{C} \mu 2$ domain suggests it is possible the arms of the DH1017.IgM pentamer can bend toward the surface of the virus and each arm can contact the epitopes at q2 $f$ and i2f of neighboring asymmetric units (Figure 5A). Such arrangement of the epitopes on the virion surface may allow Fab pairs of a pentamer arm to contact epitope pairs on the virus surface either at an $i 2 f$ and $q 2 f$ axes between neighboring asymmetric units or at the $i 2 f$ and $q 2 f$ axes within the same asymmetric unit simultaneously, allowing DH1017.IgM a decavalent mode of epitope recognition.

In the umbrella-like conformation, a theoretical maximum of three pentameric $\lg \mathrm{M}$ can bind concurrently to the same virion, occupying 30 of the 90 epitopes present on the virion surface (Figure 5B). In this bent conformation, the IgM pentamer can contact five epitope pairs compared to a single epitope pair for the recombinant DH1017.IgG due to the decavalent versus bivalent mode of antigen recognition. Alternatively, the less bent and planar pentamer conformations may bind one or more pairs of epitopes on one virus particle and bind one or more pairs of epitopes on a second virus particle (Figure 5C). This mode of binding effectively cross-links multiple virus particles into aggregates. Simultaneous engagement of five $E$ dimers at the 5 -fold axis of viral symmetry demonstrates a novel mechanism of IgM-mediated neutralization of ZIKV that is not available to an IgG molecule and may contribute to the dramatically enhanced IgM potency compared to the IgG.

\section{DH1017.IgM protects against lethal ZIKV challenge in a mouse model.}

Finally, we sought to evaluate whether DH1017. IgM could protect against ZIKV infection in mice. We administered $100 \mu \mathrm{g}$ of $\mathrm{DH} 1017 . \mathrm{IgM}$ or a non-ZIKV binding human IgM to Ifnar1-/- mice 1 day prior and 1 day following infection with 1000 FFU of ZIKV H/PF/2013 and measured viremia and lethality. We found that $\mathrm{DH} 1017 . \mathrm{IgM}$ conferred protection from lethal challenge in all mice and controlled viremia to the limit of detection (3.2-3.6 $\log _{10}$ viral copies $/ \mathrm{mL}$ ) in comparison to mice receiving control IgM (6.3-6.9 $\log _{10}$ viral copies/mL). In contrast, all mice in the control IgM group succumbed to infection (Figure 6A, B). Human IgM was maintained in vivo at detectable levels up to 4 days post challenge in both groups, or 3 days after the last administration (Figure $6 \mathrm{C}$ ).

\section{Discussion}

331 In this study, we evaluated the contribution of plasma IgM responses to ZIKV neutralization in 332 pregnancy, defined the frequency of ZIKV-specific B cells isolated from peripheral blood, and 
isolated a ZIKV-specific IgM monoclonal antibody, DH1017.IgM, in its native multimeric form. Unlike previous plasma-depleted and whole plasma investigation of IgM, the isolation of a human $\operatorname{lgM~mAb}$ in its native multimeric conformation enabled direct characterization of the impact of the IgM isotype on antibody function against ZIKV. DH1017.IgM did not cross-react with DENV 1-4 and mediated ultrapotent ZIKV neutralization. DH1017.IgM ultrapotency depended on its isotype, as it neutralized $>40$-fold more potently than when expressed as an lgG. We mapped the footprint of its discontinuous epitope within the asymmetric unit and predicted a mode of antigen recognition compatible with the concurrent engagement of all the ten antigen-binding sites present on the IgM pentamer, a solution not available to smaller lgG molecules with only two antigenbinding sites. These findings identify a unique functional niche of $\operatorname{lgM}$ antibodies in protection against ZIKV. Finally, we demonstrated in a murine model that DH1017.IgM protects from ZIKV challenge.

The humoral response to ZIKV infection, like other flaviviruses, is characterized by the development of persistent IgM serum antibodies (Gibney et al., 2012; Griffin et al., 2019; Monath, 1971; Stone et al., 2020). Recent studies have demonstrated that persisting ZIKV-specific serum IgM antibodies predominantly contribute to ZIKV neutralization (Calvert et al., 2021; Malafa et al., 2020). ZIKV infections during pregnancy are of particular concern due to the risk of congenital transmission to the fetus and subsequent burden of disease in children. Pregnancy is characterized by physiological alterations of the immune system but the characteristics of the ZIKV-specific IgM response in pregnant women remained unstudied. In our cohort of pregnant women, circulating IgM antibodies contributed to ZIKV neutralization primarily within the first 3 months of infection and as a minor contributor up to 209 DPS, which aligns with a previous report of ZIKV-specific IgM nAb dynamics outside pregnancy (Calvert et al., 2021). The temporal association (10-14 days post infection) between clearance of ZIKV infection in most individuals (Lessler et al., 2016; Paz-Bailey et al., 2018) and the early peak of serum IgM which precedes peak IgG responses (Ravichandran et al., 2019; Tonnerre et al., 2020) suggests that early lgM neutralizing responses may play an important role in early control of infection. Our data extend such temporal association in the setting of pregnancy.

We note that subject P73, from whom we isolated DH1017.IgM at day 71 DPS, developed a prolonged viremia lasting 42 days despite an early robust peak in plasma IgM neutralization. However, while viremia outlasted the first plasma IgM neutralization peak in this subject, high levels of IgM ZIKV neutralization persisted up to 71 DPS, 30 days after viremia control. The relationship between prolonged viremia and robustness of plasma lgM should be further 366 investigated.

While the role of serum IgM in flavivirus infection is actively being studied, ZIKV-specific IgM monoclonal antibodies have not been characterized, hindering our understanding of the mechanisms of action of this isotype against ZIKV. From subject P73, we derived a fully human IgM-expressing B-LCL secreting the ZIKV-specific ultrapotent DH1017.IgM nAb in its native multimeric conformation. While subject P73 had a prior exposure to DENV, DH1017.IgM did not bind to DENV and was therefore not part of a recall response from pre-existing DENV immunity. $\mathrm{DH}$ 1017.IgM was nonetheless somatically mutated. The original B cell was sorted from unfractionated B cells including naïve, class-switched, and non-class-switched memory B cells. 
Naïve B cell can undergo SHM in vitro upon EBV transformation after prolonged culturing ( $\geq 28$ days), often with evidence of clonal diversification, and can class-switch when stimulated with CD40L and IL-21 (Heath et al., 2012), which were included in our stimulation regimen. We did not identify additional nucleotide mutations or class-switched DH1017.lgG mAb from the DH1017.lgM LCL throughout multiple rounds of prolonged cell expansions. Hence, while we cannot exclude an origin from a naïve B cell, these observations suggest that DH1017.lgM LCL was derived from an IgM+ memory B cell.

Structural analysis of DH1017.Fab in complex with whole ZIKV virion identified a quaternary epitope footprint encompassing primarily DII that differs from that of known potently ZIKVneutralizing mAbs. Antibody responses targeting quaternary epitopes on multimeric $E$ protein epitopes or mature virions are associated with protection from ZIKV infection in mice (Maciejewski et al., 2020; Metz et al., 2019). Recognition of a quaternary epitope on ZIKV is the defining feature of a class of potently neutralizing mAbs (Collins et al., 2019; Hasan et al., 2017b; Long et al., 2019; Rogers et al., 2017; Sapparapu et al., 2016; Stettler et al., 2016).

Upon viral entry into cellular endosomes, E dimers rearrange into fusogenic trimers to mediate membrane fusion (Smit et al., 2011) and DH1017.lgM binding across Domain II of the E dimer may cross-link ZIKV E monomers within a single dimer and restrict conformational changes to prevent infection (Zhang et al., 2015). Such mechanism has also been proposed for ZIKV-117 and ZIKV-195 IgG mAbs (Hasan et al., 2017b; Long et al., 2019). However, our data demonstrate that IgM ultrapotent neutralization is largely depended on its isotype, implying additional nonmutually exclusive modes of isotype-dependent neutralization that are not available to lgG.

First, an IgM may efficiently cross-link multiple virions into aggregates that would not efficiently internalize into cells via endosomes. Second, the large molecular size of an lgM may interfere more efficiently than an lgG with virion attachment to the cell membrane and prevent cell entry. Third, IgM may bind with high orders of valency to a virion by virtue of its multimeric structure, thus cross-linking multiple $\mathrm{E}$ dimers. This could make the particle more rigid and sterically hinder interactions with the cell surface to prevent either binding or fusion with the host cell. Based on the position of the $\mathrm{DH} 1017 . \mathrm{lgM}$ epitope on the i2f and q2f axes of symmetry within each asymmetric unit, computational modeling of the DH1017.IgM pentamer predicts cross-linking of five $E$ dimers at the five-fold axis of symmetry resulting in a decavalent mode of antigen recognition. However, concurrent cross-linking of multiple virions and competition with other ZIKVbinding antibodies in vivo may interfere with a decavalent mode of antigen recognition on a single virion. Conversely, the pentameric IgM may out compete other less avid lgG mAbs.

Functional results together with the potential for a multivalent mode of antigen recognition suggests a functional niche that is exclusive to $\lg M$ in the context of pathogens with repetitive proximal structures. The arrangement of the cognate epitope relative to the five-fold axis of symmetry on the virion surface is essential for multivalent antibody interactions. Whether neutralizing epitopes other than the DH1017 epitope are permissive to multivalent interactions needs to be determined.

Intriguingly, class-switching to IgG of the DH1017.lgM clone would result in reduced function. Thus, we speculate that the non-class switched IgM+ memory B cell and lgM+ plasma cell pools 
could provide a source of neutralizing antibodies that interact with virions in an isotype-exclusive manner. Future studies should address if the lgM+ memory B cell compartment is a preferential source of ZIKV IgM neutralizing antibodies.

Neutralizing antibodies mediate protection against ZIKV as demonstrated in transfer of passive immunity via immune plasma in the non-human primate model (Larocca et al., 2016; Richner et al., 2017). However, IgG neutralizing antibodies at sub-neutralizing concentrations can enhance flavivirus replication via ADE through $\mathrm{Fc} \gamma \mathrm{R}$ mediated endocytosis of the immune complex. In vitro, DH1017.IgG mediated ADE, whereas DH1017.IgM did not. We note that these experimental results may be influenced by differences in the relative expression of $F c \gamma R$ and $F c \mu R / F c \alpha / \mu R$ on cell surface. In addition, DH1017. IgM in vitro neutralization potency increased in presence of complement in a dose-dependent manner. Since this complement-mediated effect lowers the stoichiometry requirements for neutralization, as previously reported for West Nile virus (Mehlhop et al., 2009), and considering the high potency of DH1017.IgM, the risk of DH1017.IgM-mediated ADE in vivo may be further reduced. Importantly, DH1017.IgM mediated protection against subcutaneously administered lethal ZIKV challenge in mice, recapitulating protection and viral control conferred by potent IgG neutralizing antibodies previously tested (Collins et al., 2019; Long et al., 2019; Robbiani et al., 2017; Sapparapu et al., 2016; Swanstrom et al., 2016).

Since efficacy trials for ZIKV vaccines are limited by currently low levels of endemic circulation, the development of prophylactic interventions that can be safely deployed to pregnant women during the next ZIKV outbreak are urgently needed to mitigate the risks of congenital ZIKV transmission. We propose that $\mathrm{DH} 1017 . \mathrm{IgM}$ may be suitable as a passive intervention for protection against ZIKV infection. In particular, since IgM isotype antibodies are not transferred across the placenta, the potential risks of fetal toxicity and ADE in infancy after transplacental lgG transfer are expected to be mitigated. Thus far, $20 \mathrm{lgM}$ mAb interventions have been tested in clinical trials and demonstrate that infused IgM are safe and well tolerated (Keyt et al., 2020).

Since the IgM half-life is considerably shorter than IgG, antibody engineering to prolong the halflife would be likely required for effective prophylactic countermeasures. However, the potential issue of short half-life would be less relevant for a therapeutic intervention administered at the time of diagnosis, which will be aimed at rapid clearance of viremia and reduction in the time of fetal exposure to circulating virus. Further, our findings support the development and investigation of engineered multimeric antibody formulations as a prophylactic and therapeutic strategy.

In summary, we demonstrated a large contribution of plasma IgM in ZIKV neutralization in both primary and DENV pre-exposed ZIKV infections in pregnancy. We isolated a novel ultrapotent ZIKV-neutralizing IgM mAb that protected mice from lethal challenge and demonstrated the impact of isotype on its antiviral function. We defined a conceptual framework by which the spatial arrangement of quaternary epitopes on the virion can modulate neutralization in an isotypespecific manner. As congenital transmission of ZIKV in pregnancy is the source of the greatest burden of ZIKV disease, further studies are warranted to assess whether DH1017. IgM can protect against fetal infection in pregnant animal models and mitigate fetal damage (Van Rompay et al., 2020) by reducing or preventing maternal viremia. With the experience of delayed roll out of vaccines to pregnant women for emerging outbreaks such as Ebola and more recently the SARS- 
CoV-2 pandemic (Craig et al., 2021; Gomes et al., 2017), a prophylactic intervention that is rapid, protective, and safe for use pregnancy will be particularly needed when ZIKV re-emerges.

Acknowledgments: This work was supported by a Duke Global Health Institute Award to S.R.P. and a Duke Incubation Fund Award to M.B.; by NIH/NIAID grants R21-Al132677 (S.R.P.), R21Al144631 (H.M.L.), F31-Al143237 (C.A.L.) and R01-Al073755 (R.J.K., PI: M.S. Diamond), by NIH/NIAID contract HHSN272201700060C (R.J.K; PI: K. Satchell) and in part by the Division of Intramural Research, NIAID, NIH (M.B.). M.B. was employed by the Duke Human Vaccine Institute (DHVI) at the time of this work and is currently employed by the Division of Intramural Research, NIAID, NIH. C.G. was supported by the Coordenação de Aperfeiçoamento de Pessoal de Nível Superior - Brasil (Finance Code 001). The pregnancy cohort in Brazil was funded by the Fundação de Amparo à Pesquisa do Espírito Santo (306/2016 to RD; Protocol Financial Support Number: 74910132/16). We thank Drs. Aravinda de Silva (UNC Chapel Hill) and James Crowe (Vanderbilt University) for sharing reagents; Madison Berry, Drs. M. Anthony Moody and Kevin Wiehe (DHVI), Brian Watts of the DHVI BIA Core Facility and the DHVI Research Flow Cytometry Facility for helpful scientific discussions and/or logistical and technical support. Also, we thank Juliana Carnielli, Solange Alves Vinhas and Keyla Fonseca for establishing cohort enrollment and sample collections at Federal University of Espírito Santo. We are grateful to the maternity ward of Cassiano Antonio de Moraes Hospital staff for supporting the participants' deliveries and birth sample collections. Importantly, we thank the mothers who participated in this study and made efforts to provide samples for research during pregnancy.

Declaration of interests: M.B., S.R.P., T.S. and K.K.H. have filed a patent application directed to antibodies that are related to this work. S.R.P. is serving as a consultant for vaccine programs at Merck, Pfizer, Moderna, Dynavax and Hoopika. All other authors declare no conflict of interest.

Contributions: Conceptualization, T.S., R.D., S.R.P. and M.B.; Methodology, T.S., A.S.M., C.A.L., L.P., R.D., H.M.L., R.J.K., S.R.P. and M.B.; Investigation, T.S., K.K.H., A.S.M., R.L.J., C.A.L., M.A.G., I.M., H.S.W., J.A.E., K.L., T.V.H., R.J.E., S.V., K.E.B., S.Z., J.F.M., J.J.T., M.D., L.P. and M.B.; Resources, C.G., L.P., R.D., T.C.P., E.E.O., H.M.L., S.R.P. and M.B.; Writing Original Draft, T.S., A.S.M., S.R.P. and M.B.; Writing - Review \& Editing, all authors; Visualization, T.S., A.S.M., C.A.L. and M.B.; Supervision, T.C.P., E.E.O., H.M.L., R.J.K., S.R.P. and M.B.; Funding Acquisition, C.A.L., C.G., R.D., H.A.L., R.J.K., S.R.P and M.B. 


\section{Methods}

Donors and Sample Information. Participants in this study were enrolled from July 2016 to October 2017 in the city of Vitória, State of Espírito Santo, in Brazil. In this prospective cohort, we enrolled pregnant women with Zika-like symptoms of rash and/or fever and collected blood samples through pregnancy, delivery, and postpartum. Cohort design, recruitment, enrollment and sample collection are detailed in our prior study (Singh et al., 2019). Plasma and peripheral blood mononuclear cells (PBMCs) from 11 mothers who were serologically confirmed for ZIKV infection previously (Singh et al., 2019) were included in this study. The identifiers of the subjects included in this study are as follows (alternative identifiers in parenthesis): P14 (B1_0001), P15 (B1_0002), P17 (B1_0004), P19 (B1_0005), P23 (B1_0007), P24 (B1_0008), P34 (B1_0014), P50 (B1_0027), P54 (B1_0027), P56 (B1_0031) and P73 (B1_0037). The infant born to subject P14 demonstrated microcephaly at birth, and the rest had no known signs of congenital Zika syndrome. DH1017.IgM was isolated from the PBMCs of P73, who presented with a symptomatic ZIKV infection at 22 weeks of gestation and had prolonged viral replication with vRNA detected in serum/urine up to 42 DPS. She delivered an apparently healthy baby at 38.5 weeks of gestation with normal head circumference. All other mothers had detectable ZIKV vRNA in plasma at the first visit only.

Ethics Statement. The Institutional Review Boards of Hospital Cassiano Antonio Moraes (Brazilian National Research Ethics Committee (CEP/CONEP) Registration number: 52841716.0.0000.5071) and the Duke University Medical Center (Pro00100218) each approved this prospective cohort study and sampling. Pregnant women with rash or fever, who were a minimum of 18 years of age, and provided a willingness to participate through a written informed consent were approved for inclusion into this study. To protect the privacy of all subjects, publicly available identifiers are twice removed from the participant. All practices conducted as part of this study are compliant with ethical principles for medical research involving human subjects as outlined in the Declaration of Helsinki.

Animal work was approved by the University of North Carolina at Chapel Hill IACUC (protocol no. 20-132).

Cell culture and virus stocks. Vero-81 cells were grown in Dulbecco's Modified Eagle Media (Gibco 11965092) supplemented with $10 \%$ heat-inactivated fetal bovine serum (Sigma, F4135$500 \mathrm{~mL}$ ), 1x penicillin-streptomycin (Gibco 15140-122), and 1x MEM non-essential amino acids solution (Gibco 11140-050). Viruses used for the focus reduction neutralization test were DENV1 (WestPac74), DENV2 (S-16803), DENV3 (CH54389), DENV4 (TVP-360), provided by Dr. Aravinda de Silva (University of North Carolina at Chapel Hill); ZIKV H/PF/2013 and PRVABC59 strains were obtained from the Biodefense and Emerging Infections Research Resources Repository (BEI). Virion binding antibodies were detected using the following viruses from BEI: ZIKV (PRVABC59), DENV1 (Hawaii NR-82), DENV2 (New Guinea C), DENV3 (Philippines), and DENV4 (H241). ZIKV was grown in Vero-81 cells supplemented with $10 \%$ heat-inactivated fetal bovine serum (FBS) and 10mM HEPES (Sigma H0887-100ML). Dengue viruses were grown in C6/36 cells cultured in RPMI 1640 (Gibco 11875-093), L-Glutamine (Gibco 25030-081), 25 mM HEPES (Gibco, 22400-089), 1x penicillin-streptomycin (Gibco, 15140-122), and 20\% FBS. 
During DENV infection, RPMI was supplemented with 25mM HEPES and $2 \%$ FBS. $0.5 \mathrm{~mL}$ of viruses were added to $80-90 \%$ confluent cells. Cells were infected with DENV2, DENV3, or DENV4 for 7-9 days and DENV1 for 11 days. ZIKV stock infections were stopped when cytopathic effect was observed ( 3-6 day infection). Cell supernatant containing virus was then harvested, centrifuged brought to a final concentration of $20 \%$ FBS, and filtered through $0.22 \mu \mathrm{m}$ filter prior to storage at $-80^{\circ} \mathrm{C}$ for use. Fc $\gamma$ R-expressing $\mathrm{K} 562$ cells and THP-1 cells were maintained in RPMI 1640 medium containing Glutamax (Invitrogen) with 7\% heat-inactivated FBS (Invitrogen) and 1X penicillin-streptomycin (Invitrogen).

Fluorescent labelling of ZIKV for sorting B cells. A previously developed approach to label DENV with Alexa Fluor 488 (AF488) dye was adapted to label ZIKV (Zhang et al., 2010). ZIKV (Strain: PF13/251013-18) was propagated in Vero cells and purified through $30 \%$ sucrose. Virus titer was determined using the BHK-21 cell plaque forming assay as previously described (Chan et al., 2011). Briefly, AF488 succinimidyl ester was reconstituted in 0.2M sodium bicarbonate buffer ( $\mathrm{pH}$ 8.3) and added to $3 \times 10^{8} \mathrm{PFU}$ of ZIKV at a final dye concentration of $100 \mu \mathrm{M}$. The mixture was incubated at room temperature for 1 hour with gentle inversions every 15 minutes. Labelled ZIKV was purified by size exclusion chromatography using Sephadex G-25 columns (Amersham, GE Healthcare) to remove the excess dye and titrated again on BHK-21 cells. Thereafter, ZIKV was UV inactivated $(254 \mathrm{~nm})$ for 1 minute on ice. Inactivation of virus was verified by serial passaging of virus on C6/36 mosquito cell line (ATCC), without detection of infection on this susceptible cell line.

Staining and sorting ZIKV-reactive B cells. Thawed PBMCs were stained with Aqua Vital Dye (Invitrogen), IgD-PE (clone IA6-2; BD Biosciences), CD10 PE-CF594 (clone HI10a; BD Biosciences; CD3 PE-Cy5 (clone HIT3a; BD Biosciences), CD14 BV605 (clone M5E2; BD Biolegend), CD16 BV570 (clone 3G8; Biolegend), CD27 PE-Cy7 (clone O323; Thermo Fisher Scientific), CD38 APC-AF700 (clone LS198-4-3; Beckman Coulter), CD19 APC-Cy7 (clone SJ25C1; BD Biosciences) and $1 \times 10^{6} \mathrm{PFU}$ of freshly thawed UV-inactivated ZIKV labelled with AF488. Additionally, $5 \mu \mathrm{M}$ of Chk2 kinase inhibitor II Inhibitor (Calbiochem/EMD Chemicals) was added to prevent cell death. Unfractionated B cells were defined as CD14/CD16/CD3//CD19 ${ }^{+}$. For memory B cells an additional IgD $/ C D 27^{\text {all }}$ gate was applied. The ZIKV-reactive AF488 gate was set using a fluorescence minus one condition. Cells were sorted on a Beckton Dickinson FACS Aria II and analysis was performed in FlowJo.

B cell cultures. ZIKV-reactive B cells were cultured as previously described (Bonsignori et al., 2011, 2016). Briefly, cells were sorted in wells pre-seeded with human CD40 ligand-expressing

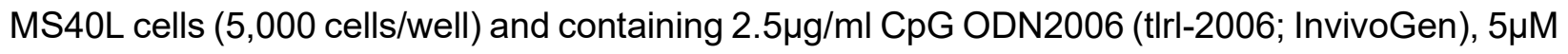
CHK2 kinase inhibitor II) and $50 \mathrm{ng} / \mathrm{ml}$ of recombinant human (rHu) IL-21 (200-21; Peprotech) in $\mathrm{RPMI} / 15 \%$ fetal calf serum. EBV was added for the overnight incubation $(200 \mu$ l supernatant of B95-8 cells per $10^{4} \mathrm{~B}$ cells). After overnight incubation in bulk at $37^{\circ} \mathrm{C}$ in $5 \% \mathrm{CO}_{2}$, B cells were distributed by limiting dilution at a calculated concentration of 1 cell/well into 96-well round-bottom tissue culture plates in the presence of MS40L cells and complete medium described above. Medium was refreshed after 7 days. Supernatants were collected after 14 days. Cell culture supernatants were assessed for IgG, IgM, and IgA levels in ELISA as previously described (Bonsignori et al., 2016) and lg+ wells were further evaluated for ZIKV-reactivity with a virion 
binding ELISA. From each culture well, half of the cells were harvested and preserved in RNAlater (Qiagen) at day 14 and half were maintained in culture. Cell clones that immortalized were expanded and cloned by using a standard limiting dilution method. Reactivity and $\operatorname{lgV}(\mathrm{D}) \mathrm{J}$ sequences were checked periodically. We derived three IgG+ B-LCLs from P34 (termed 119-4D6.lgG, 119-1-D7.lgG, and 119-5-C5.lgG), three IgG+ B-LCL from P56 (124-4-C8.lgG, 124-1C2.IgG and 124-2-G3.lgG), and one IgG+ B-LCL from P54 (126-1-D11.lgG), From subject P73 we derived two B-LCLs: one expressing IgG from memory B cells collected 28 DPS (123-3G2.lgG), and one IgM+ B-LCL (termed DH1017) from unfractionated B cells collected at 71 DPS.

Isolation of $\mathbf{V}(\mathrm{D}) \mathrm{J}$ immunoglobulin regions. RNA from positive cultures was extracted by using standard procedures (RNeasy minikit; QIAGEN), and the genes encoding Ig $V_{H} D J_{H}$ and $V_{L} J_{L}$ rearrangements were amplified by $R T$ and nested PCR without cloning by use of a previously reported method (Liao et al., 2009). Ig V(D)J sequences (Genewiz) were assembled using a customized bioinformatic tool developed by Kevin Wiehe (DHVI) based on the Cloanalyst software package (http://www.bu.edu/computationalimmunology/research/software/).

Monoclonal antibody production. B-LCLs were expanded in CELLine bioreactor flasks (Wheaton) following the manufacturer's recommendations. Monoclonal antibodies were purified using protein $A$ resin columns for IgG and CaptureSelect beads (Thermo Scientific) for DH1017.IgM following manufacturer's recommendations. DH1017.IgG and DH1017.Fab heavy and light chain plasmids (GenScript) were co-transfected at an equal ratio in suspension Expi 293i cells (Invitrogen) using ExpiFectamine 293 transfection reagents (Life Technologies) according to the manufacturer's protocols. Transfected cells were gently shaken overnight for 1618 hours and incubated at $37^{\circ} \mathrm{C}$ with $8 \% \mathrm{CO}_{2}$. We then added the enhancer provided in the kit and incubated at $37^{\circ} \mathrm{C}$ with $8 \% \mathrm{CO}_{2}$ for $4-6$ days. Supernatant containing antibody was harvested and filtered, and co-incubated with a Protein A affinity resin (Thermo Fisher Scientific) for IgG antibody or LambdaFabSelect Agarose Beads (GE Healthcare Life Sciences) for Fab at $4^{\circ} \mathrm{C}$ on a rotating shaker overnight. The bead and supernatant mixture was then loaded onto a column for purification. Following a Tris/ $\mathrm{NaCl}$ Buffer $(\mathrm{pH}$ 7.0) wash, mAb was eluted from beads using Trizma HCl (pH 8.0; VWR) and concentrated in the Vivaspin Turbo 15 Concentrator (Thermo Fisher Scientific) with a pH neutralizing buffer exchange using Citrate Buffer (pH 6.0). Purified antibody concentration was determined by Nanodrop and product was evaluated by reducing and nonreducing SDS-polyacrylamide gel electrophoresis and Coomassie Blue staining for appropriate size.

SDS PAGE and Coomassie. DH1017.IgM was run under non-reducing conditions using a NuPAGE 3-8\% Tris-Acetate Gel (Invitrogen) with 1x Tris-Glycine Native Running Buffer (Novex)

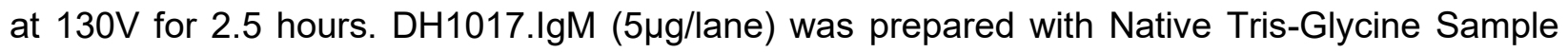
Buffer (Novex) and NativeMark Protein Standard (Invitrogen) was used as the ladder. Gel was subsequently stained with Coomassie and imaged using ChemiDoc (Bio-Rad).

Negative stain electron microscopy. An aliquot of DH1017.IgM was equilibrated to room temperature, then diluted to $20-40 \mu \mathrm{g} / \mathrm{ml}$ with buffer containing $10 \mathrm{mM} \mathrm{HEPES}, \mathrm{pH} 7.4,150 \mathrm{mM}$ $\mathrm{NaCl}$, and $0.02 \%$ ruthenium red. A $5 \mu \mathrm{l}$ drop of diluted sample was applied to a glow-discharged carbon-coated grid for 8-10 seconds, blotted, then rinsed with two drops of buffer containing 1 
mM HEPES, $\mathrm{pH} 7.4$ and $7.5 \mathrm{mM} \mathrm{NaCl}$, and finally stained with one drop of $2 \%$ uranyl formate for $60 \mathrm{~s}$, then blotted and air dried. Images were obtained with a Philips EM420 electron microscope at $120 \mathrm{kV}, 82,000 \times$ magnification, and captured with a $2 \mathrm{k} \times 2 \mathrm{k}$ CCD camera at $4.02 \AA /$ pixel. The RELION program (Scheres, 2016) was used for particle picking and 2D class averaging.

ZIKV and DENV virion capture ELISA. The virion capture ELISA methods were previously described (Singh et al., 2019). Briefly, high-binding 96-well plates (Greiner) were coated with 40 ng/well of 4G2 antibody (clone D1-4G2-4-15) in 0.1 M carbonate buffer, pH 9.6 overnight at $4^{\circ} \mathrm{C}$. Plates were blocked in Tris-buffered saline containing $0.05 \%$ Tween-20 and $5 \%$ normal goat serum for 1 hour at $37^{\circ} \mathrm{C}$, followed by an incubation with either ZIKV (PRVABC59), DENV1 (Hawaii), DENV2 (New Guinea C), DENV3 (Philippines), and DENV4 (H241) from BEI for 1 hour at $37^{\circ} \mathrm{C}$. ZIKV and DENV2 were diluted 1:5, DENV1 and DENV3 diluted 1:3, and DENV4 diluted 1:7. $50 \mu \mathrm{L} /$ well samples were added and incubated for 1 hour at $37^{\circ} \mathrm{C}$. Culture supernatants were screened undiluted whereas plasma and purified $\mathrm{mAb}$ binding was measured in duplicate. Eightpoint serial dilutions for plasma started at 1:25 with 3-, or 5-fold dilutions and mAbs started at 100 $\mathrm{ug} / \mathrm{mL} 5$-fold serial dilutions. Horseradish peroxidase (HRP)-conjugated goat anti-human IgG antibody (Jackson ImmunoResearch Laboratories, 109-035-008), HRP-conjugated goat antihuman IgM antibody (Jackson ImmunoResearch Laboratories, 109-035-129), or HRP-conjugated goat anti-human IgA antibody (Jackson ImmunoResearch Laboratories, 109-035-011) were all used at a 1:5,000 dilution followed by the addition of SureBlue Reserve TMB substrate (KPL, Gaithersburg, MD). Reactions were stopped by Stop Solution (KPL) after five minutes and optical density (OD) was detected at $450 \mathrm{~nm}$ (Perkin Elmer, Victor). For IgG and IgM, an isotype matched known ZIKV-specific commercial mAb was used as a positive control (IgG: C10, Absolute Antibody, Cat \#: AB00677-10.0; IgM: Anti NS1 IgM, myBiosource, Cat\#: MBS6120634). Plasma from ZIKV-infected individuals was used as positive control for IgA culture supernatants. The negative control condition was sample diluent alone. Respiratory syncytial virus specific IgG Palivizumab was used as a negative control for testing ZIKV-binding of purified mAbs, and diluent served as negative control for IgM purified mAb assays. For purified mAbs that were serially diluted, the magnitude of virion binding was evaluated as an $E D_{50}$, which was calculated with a sigmoidal dose-response (variable slope) curve in Prism 7 (GraphPad) using a least squares fit. The $\mathrm{ED}_{50}$ value for serially diluted mAbs was considered valid if the $\mathrm{OD}_{450}$ at $100 \mathrm{ug} / \mathrm{mL}$ was 5fold higher than the no sample condition. For plasma, the $E D_{50}$ value was considered valid if the $\mathrm{OD}_{450}$ at 1:25 dilution 2 standard deviations above the mean $\mathrm{OD}_{450}$ for DENV 1-4, and 3 standard deviations above the mean $\mathrm{OD}_{450}$ observed for 11 plasma samples from healthy U.S. subjects (2SD OD 450 cut-offs: DENV-1 = 0.406, DENV-2 = 0.648, DENV3 = 0.906, and DENV-4 = 0.885; $3 S D O_{450}$ cut-off: ZIKV = 0.596). For culture supernatants, the cut-off for positivity was the highest of mean plate blanks $\mathrm{OD}_{450}+2$ standard deviations and $\mathrm{OD}_{450}$ not less than 0.4 .

Recombinant E protein ELISA. DH1017 mAbs was immobilized to a high-binding 96-well plate (Greiner) at $0.5 \mathrm{ug} / \mathrm{mL}$ in $1 \mathrm{x}$ TBS, then blocked with $3 \%$ milk in TBS tween, each for 1 hour at $37^{\circ} \mathrm{C}$. Serial dilutions of his-tagged recombinant $\mathrm{E}$ protein dimer (Premkumar et al., 2017) starting at $20 \mathrm{ug} / \mathrm{mL}$ with 2-fold dilutions to 12-spots were added to the plate for an hour at $37^{\circ} \mathrm{C}$. This was followed by $0.5 \mathrm{ug} / \mathrm{mL}$ anti-his HRP (Sigma), and binding was detected after incubation with substrate at an absorbance of $450 \mathrm{~nm}$. EC $\mathrm{E}_{50}$ was obtained by a sigmoidal dose-response (variable 
slope) curve in Prism 7 (GraphPad) using least squares fit. The negative control was no antigen and positive control were previously reported mAbs, including 1M7, ZV-2, ZV-64 and ZKA190. $1 \mathrm{M} 7 \mathrm{mAb}$ (Smith et al., 2013) was produced from a hybridoma. ZKA190 was generated recombinantly using the sequence for PDB entry 5Y0A (Wang et al., 2017). The mouse mAbs ZV-2 and ZV-64 (Zhao et al., 2016) were produced from hybridomas at the UNC protein expression core facility. ZIKA-752, ZIKA-893, and rZIKV-195 were produced and provided by James Crowe.

Focus reduction neutralization test. We used previously described methods for $\mathrm{FRNT}_{50}$ in a 96-well plate (Singh et al., 2019). Briefly, serial dilutions of heat-inactivated plasma or purified mAbs were added to 30-60 focus forming units of either DENV serotypes 1-4 or ZIKV (H/PF/2013). Plasma was used at a starting dilution of 1:25 with subsequent 5 -fold or 7-fold dilutions. MAbs were tested at $5 \mathrm{ug} / \mathrm{mL}$ or $10 \mathrm{ug} / \mathrm{mL}$ with 5 -fold dilution series. However, $\mathrm{DH} 1017 . \mathrm{Fab}$, was tested at $1 \mathrm{mg} / \mathrm{mL}$ with a 5 -fold dilution series. Negative control was media alone, and positive controls were known ZIKV-neutralizing mAbs and plasma from ZIKV-infected subjects. Virus and plasma or mAb samples were co-incubated for 1 hour at $37^{\circ} \mathrm{C}$, then transferred to a 96-well plate (Greiner Bio One) with confluent Vero-81 cells and incubated for 1 hour at $37^{\circ} \mathrm{C}$. Plates were overlayed with $1 \%$ methylcellulose and incubated at $37^{\circ} \mathrm{C}$ for $40-42$ hours (ZIKV and DENV4), 51-53 hours (DENV1), or 48 hours (DENV2 and DENV3). Cells were fixed with $2 \%$ paraformaldehyde for 30 minutes and stained with $0.5 \mu \mathrm{g} / \mathrm{mL}$ of $4 \mathrm{G} 2$ or E60 mouse monoclonal antibody. Foci were detected with an anti-mouse $\lg G$ conjugated to horseradish peroxidase at a 1:5000 dilution (Sigma), followed by True Blue substrate (KPL). Foci were counted using the CTL ImmunoSpot plate reader (Cellular Technology Limited). FRNT 50 values were calculated with the sigmoidal dose-response (variable slope) curve in Prism 8.3.0 (GraphPad), constraining values between 0 and $100 \%$ relative infection. Percent relative infection curves were considered to pass quality control criteria for $F R N T_{50}$ determination if $R^{2}>0.65$, absolute value of hill slope $>0.5$, and curve crossed $50 \%$ relative infection within the range of the plasma dilutions in the assay. Samples were repeated up to 3 times to quantify a valid FRNT $_{50}$ in accordance with the quality control criteria.

Reporter Virus Particle (RVP) production. ZIKV RVPs incorporating the structural proteins (Capsid [C], premembrane [prM], and E) of ZIKV strain H/PF/2013 were produced by genetic complementation of a green fluorescent protein (GFP)-expressing WNV lineage II sub-genomic replicon with the virus structural gene plasmids as previously described (Dowd et al., 2016). Briefly, the WNV replicon and C-prM-E plasmids were co-transfected into HEK-293T cells using Lipofectamine $3000^{\mathrm{TM}}$ transfection reagent (Invitrogen). Transfected cells were incubated at $30^{\circ} \mathrm{C}$ and RVP-containing supernatants were harvested 3-6 days post-transfection and pooled. RVPcontaining supernatants were passed through a $0.2 \mu \mathrm{m}$ filter (Millipore) and stored at $-80^{\circ} \mathrm{C}$ until use.

RVP-based Antibody-Dependent Enhancement (ADE) assay. RVP-based ADE assays were performed by incubating GFP-encoding RVPs with serial dilutions of $m A b s$ for $1 \mathrm{~h}$ at $37^{\circ} \mathrm{C}$. Fc $\gamma \mathrm{R}+$ K562 or THP-1 cells were infected with RVP immune complexes and incubated at $37^{\circ} \mathrm{C}$ for 36 $48 \mathrm{~h}$. Cells were fixed with paraformaldehyde, and GFP expression was detected by flow cytometry. Antibody enhanced infection was scored as detectable if the number of GFP positive 
cells was $\geq 3$-fold above background (defined as the average percent GFP positive cells in the absence of antibody).

Plaque assay-based ADE assay. DH1017.IgM and DH1017.IgG were serially diluted 2-fold over $6.25-0.003 \mu \mathrm{g} / \mathrm{mL}$ and $10 \mathrm{uL}$ of diluted $\mathrm{mAb}$ were co-incubated in duplicate with $2 \times 10^{5} \mathrm{PFU}$ of ZIKV (Strain: PD13/251013-18) in a round bottom 96 well-plate for 1 hour at $37^{\circ} \mathrm{C}$ to form immune complexes. Thereafter, $2 \times 10^{4}$ cells of THP1.2S or primary monocytes were added to the ZIKV and $\mathrm{mAb}$ immune complexes for a 72-hour multiday infection at $37^{\circ} \mathrm{C}$. THP1.2S cells are a subclone of the THP1 monocyte cell line (ATCC) that are shown to be more susceptible to flavivirus infection (Chan et al., 2014). Collection and processing of primary monocytes has been previously described and was conducted approval of the NUS Institutional Review Board under reference code B-15-227 (Chan et al., 2019). After the multiday infection on monocytes, supernatant was collected, and infectious virus was tittered via plaque forming assays on BHK-1 cells (ATCC) in 24 well plates in quadruplicate, as previously described (Chan et al., 2011). For the positive control we used humanized IgG1 4G2 mAb, and for the negative control we used 3H5 (DENV-specific mAb) as well as the virus only condition, without any mAb present.

Antibody-dependent complement antiviral activity. Focus reduction neutralization test (FRNT) in the presence of increasing concentrations [volume/volume] of complement from normal human serum (Sigma), including 0, 5, 10, 15, 20 and 25\% final concentration were tested. Percent relative infection was calculated as a ratio of the foci in the plasma, ZIKV (PRVABC59), and complement condition, to the foci in the virus and complement condition, multiplied by 100 . This approach allows for determination of the antibody-dependent complement activity and adjusts for antibody-independent complement activity. Samples were run in triplicate and experiment was independently repeated for each concentration of complement. Positive control was DH1017.lgM and DH1017.lgG run in the absence of complement, and negative control was the virus and complement only conditions. The rest of the analysis and approach are identical to the FRNT approach.

Determining the contribution of plasma IgM to ZIKV neutralization. Each original plasma sample was split into 2 aliquots, with one portion depleted of IgM isotype antibodies and another portion mock depleted. First, each sample was heat inactivated for 30 minutes at $56^{\circ} \mathrm{C}$, diluted $1: 1$ with sterile PBS, and centrifuged at $10,000 \times \mathrm{G}$ for 10 minutes to remove debris. Depletion beads were packed into sterile $0.5 \mathrm{~mL}$ centrifugal filter devices with a $0.22 \mu \mathrm{m}$ pore PVDF membrane (Millipore) and equilibrated with $3 x$ sterile PBS washes ( $\mathrm{pH} 7.2$ ). 200mg of POROS ${ }^{\mathrm{TM}}$ CaptureSelect ${ }^{\mathrm{TM}}$ IgM affinity beads (ThermoFisher Scientific) were used for IgM depletion, and $66 \mathrm{mg}$ of corresponding beads of the same size (200-400 mesh) and material (polystyrene divinylbenzene $1 \%$ cross linked beads; Alfa Aesar) were used for mock depletion. Samples were co-incubated with beads for 10 minutes at room temperature with gentle inversions, and then the depleted fraction was centrifuged at $10,000 \times g$ for 10 minutes.

Depletion of IgM was confirmed by total IgM ELISA, and non-specific losses to ZIKV-binding IgG were quantified through virion binding ELISA; both assays are described in other sections of this Method supplement. Limit of detection (LOD) of $0.12 \mu \mathrm{g} / \mathrm{mL}$ was based on the linear range of a sigmoidal standard curve of human IgM (Jackson ImmunoResearch Laboratories). Magnitude of 
ZIKV-binding IgG was assessed by virion-binding ELISA and neutralization potency was assessed using the Focus Reduction Neutralization Test. Due to slight differences in ZIKVbinding lgG across lgM and mock depleted fractions, each fraction was adjusted to the magnitude of ZIKV-binding IgG in the same sample such that differences in neutralization activity could be attributed to differences in IgM isotype antibodies. Thus, the percent neutralization attributable to $\lg \mathrm{M}$ that is reported in this study was calculated as follows:

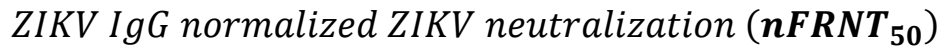

$$
=\frac{Z I K V \text { neutralizing titer }\left(F R N T_{50}\right)}{Z I K V \text { specific } \operatorname{Ig} G\left(E D_{50}\right)}
$$

Percent ZIKV neutralization attributable to IgM (\%)

$$
=100 \times \frac{\text { Mock depleted } n F R N T_{50}-{\text { IgM depleted } n F R N T_{50}}_{\text {Mock depleted } n F R N T_{50}}}{\text { Mock }}
$$

Detection of antibody isotype from sera. Human IgM antibodies were detected in sera from passively transferred mice using high-binding 384-well plates (VWR) coated with $0.5 \mu \mathrm{g} / \mathrm{well}$ of goat anti-human Ig polyvalent antibody (ThermoFisher, \#H17000) in $0.1 \mathrm{M}$ carbonate buffer, pH 9.6 overnight at $4^{\circ} \mathrm{C}$. Plates were blocked the next day ( 2 hours at RT) with 10X PBS containing $4 \%$ whey, $15 \%$ normal goat serum, and $0.5 \%$ tween. Mouse serum samples were diluted 1:30, serially diluted three-fold, then added to the plate $(10 \mu \mathrm{L} /$ well $)$, and incubated for 1 hour at $37^{\circ} \mathrm{C}$. Horseradish peroxidase (HRP)- conjugated goat anti-human IgM antibody (Jackson

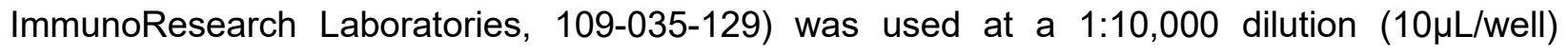
followed by the addition of SureBlue Reserve TMB substrate (KPL). Reactions were stopped by Stop Solution (KPL, Gaithersburg, MD) after five minutes and optical density (OD) was detected at $450 \mathrm{~nm}$ (Perkin Elmer, Victor). DH1017.IgM was used as a positive control and standard. Blank wells were used as a negative control. Antibody concentrations were interpolated from the standard curve, which was fit using to a 5-parameter fit sigmoidal curve (SoftMax Pro 6.3; Molecular Devices). Concentrations were interpolated from $\mathrm{OD}_{450}$ values within the linear range of the sigmoidal curve at dilution 90, or alternatively 30, for samples at 2-6 DPI, and at dilution 10 for samples at 8+ DPI. A passing quality control criterion of replicate $\mathrm{OD}_{450}$ values less than or equal to $25 \%$ variance was applied. Limit of detection for this assay was $0.08 \mu \mathrm{g} / \mathrm{mL}$ across assays, based on the linear range of the standard curve.

To measure concentration of IgM from human plasma, the same assay was applied with the following modifications. All original and lgM/mock depleted samples were diluted 1:30 relative to original plasma with 3-fold serial dilutions. Human IgM (Jackson ImmunoResearch Laboratories, 009-000-012) was used as positive control and standard. IgM concentration in sample was inferred based upon the 1:2430, or alternatively the 1:270 and 1:810 serum dilutions, which were all in the linear range of the standard curve.

Biolayer interferometry. BLI assays were performed on the ForteBio Octet Red96 instrument at $25^{\circ} \mathrm{C}$ with a shake speed of 1,000 RPM. Goat Anti-Human Ig polyvalent $(20 \mu \mathrm{g} / \mathrm{mL}$; Thermo 
Fisher) was amine coupled to AR2G sensor tips as follows: sensor tips were activated with sNHS/EDC (300s), incubated in Anti-Human Ig (600s), and quenched with ethanolamine (300s). DH1017.lgM, DH1017.lgG, and a negative control lgG (palivizumab) were diluted to $50 \mu \mathrm{g} / \mathrm{mL}$ in PBS and captured on the biosensors (300s), followed by a PBS wash (60s). A baseline signal was recorded for $2 \mathrm{~min}$ in PBS ( $\mathrm{pH} 7.4$ ). Biosensors were then immersed into a two-fold dilution series of ZIKV E protein dimer in PBS $(50-0.78 \mu \mathrm{g} / \mathrm{mL})$ to measure association (400s), followed by immersion into PBS to measure dissociation (600s). All binding profiles were corrected by double reference subtraction using the signal obtained in a PBS control (without E proteins) and the signal obtained from the Palivizumab control sensor. All affinities were calculated using the fast kinetic components of the heterogeneous ligand model fit. Kinetics and affinity data are the result of a single measurement.

Size exclusion chromatography. ZIKV E dimer was screened for size on Superdex 200 Inc $10 / 300$ GL column: $100 u L$ of $E$ dimer was loaded onto the column at $0.13 \mathrm{mg} / \mathrm{mL}$ and was run at a flow rate of $0.5 \mathrm{~mL} / \mathrm{min}$ in PBS.

Virus propagation and purification for cryo electron microscopy. ZIKV strain H/PF/2013 was propagated in Vero-Furin cells (Mukherjee et al., 2016). Approximately $10^{9}$ Vero-Furin cells, grown in 10\% FBS (Sigma, F0926), Dulbecco's modified Eagle medium (DMEM) media (Thermofisher, 41300039) and $50 \mathrm{ug} / \mathrm{mL}$ blasticidin (Invivogen, anti-bl-1) at $37^{\circ} \mathrm{C} 5 \% \mathrm{CO}_{2}$, were infected with a $\mathrm{MOI}$ of 0.1 . Virus particles in $2 \%$ FBS/DMEM/1mM Pen/Strep (Thermofisher, 15140122) were incubated with cells for 2 hours at room temperature. After 2 hours, infected cells were incubated at $37^{\circ} \mathrm{C}, 5 \% \mathrm{CO}_{2}$ for 36 hours. At 36 hours post infection (hpi), infectious media was collected and replaced with fresh media every 12 hours up to 84 hpi. Virus particles were purified from media collected at 60 and $72 \mathrm{hpi}$.

Briefly, cell debris were pelleted by centrifugation at $2,744 \mathrm{x} g$ for 30 minutes. Infectious media was filtered with through a Steritop-GP $0.2 \mu \mathrm{m}$ filter (Millipore, SCGPT05RE) and virus particles were precipitated overnight at $4^{\circ} \mathrm{C}$ with PEG $4000,8 \%$ final concentration. PEG precipitated particles were concentrated at $8,891 \times \mathrm{g}$ for 50 minutes. Particles were concentrated through a $24 \%$ sucrose cushion by ultra-centrifugation at $126,144 \times g$ for 2 hours at $4^{\circ} \mathrm{C}$. Virus particles were isolated with a discontinuous potassium-tartrate/glycerol/NTE buffer $(120 \mathrm{mM} \mathrm{NaCl}, 20 \mathrm{mM}$ Tris $\mathrm{pH} 8.0,1 \mathrm{mM}$ EDTA) gradient in $5 \%$ increments between $35 \%$ and $10 \%$ potassium-tartrate and ultra-centrifugation at $126,144 \times g$ for 2 hours at $4 \mathrm{C}$. The particles were extracted from the $20 \%$ fraction of the discontinuous gradient and buffer exchanged and concentrated in NTE buffer with a $100 \mathrm{kDa}$ MWCO centrifugal filter.

Single particle cryoelectron microscopy. Prior to freezing, purified virus and DH1017.Fab fragments were incubated on ice for 2 hours at a molar ratio of $0.2 \mathrm{mM}$ Fab to $1 \mathrm{mM} \mathrm{E}$ protein. Samples were then plunge frozen in liquid ethane using a Cryoplunge 3 System (GATAN). Briefly, liquid nitrogen was used to liquefy ethane at $-190^{\circ} \mathrm{C}$. A $2.5 \mu \mathrm{L}$ volume of sample was spotted on lacey carbon grids (Ultrathin C on Lacey Carbon Support film, 400 mesh, Cu. Ted Pella, Inc. Product number 01824) and blotted with Whatman grade 1, 200mm circle filter paper (GE Healthcare Life Sciences, catalog number 1001-020) for 2.5 seconds. Blotting air pressure setting used was 100 psi. 
818

819

820

821

822

823

824

825

826

827

828

829

830

831

832

833

834

835

836

837

838

839

840

841

842

843

844

845

846

847

848

849

850

851

852

853

854

855

856

857

858

859

Data were collected on a Titan Krios (Thermofisher) microscope equipped with a Gatan K3 detector using and Leginon software package (Suloway et al., 2005). A total of 1,929 cryo EM micrographs were collected with a nominal magnification of $64000 x, 0.66 \AA$ Apixel size, and an electron dose equivalent, of $35 \mathrm{e}-/ \AA 2$. Motion correction and CTF calculations estimations were performed using MotionCorr2 (Zheng et al., 2017) and CTFFIND4 (Rohou and Grigorieff, 2015) respectively.

Automated particle selection picking (Sigworth, 2004) performed with cisTEM (Grant et al., 2018) selected 34,474 particles. A maximum-likelihood algorithm based 2D classification (Scheres et al., 2005; Sigworth, 1998) was performed with using cisTEM. From a subset of 2D classes, 4104 particles were selected for further processing.

Single particle reconstruction was performed according to the 'gold standard' method using jspr (Guo and Jiang, 2014). Briefly, the particles were divided equally into two randomly selected independent particle sets. Twenty ab-initio models were generated from a random set of 700 particles selected from the set of 4,104 particles. Two ab-initio models were selected, and one ab-initio model was assigned to one independent particle set and the other ab-initio model was assigned to the other independent data set. Each dataset was refined iteratively assuming icosahedral symmetry. Refinement resulted in two independent models that converged on the same structure. Following corrections for astigmatism, elliptical distortion, defocus, and the masking of the disordered nucleocapsid core, the final models of each independent data set were combined into a single final model. The resolution of the map was calculated at 0.143 from the FSC curve (Rosenthal and Henderson, 2003).

Model fitting, refinement, and structure analysis. Models used in fitting viral structural proteins in the cryo EM density map are the E glycoprotein ectodomain of the ZIKV asymmetric unit (PDB 6CO18) (Sevvana et al., 2018) and a homology model of DH1017.Fab fragment. The Fab fragment model is composed of individual domains variable heavy, variable light, $\mathrm{C}$, and lambda domains. The homology models of each Fab fragment domain were generated with I-TASSER (Roy et al., 2010; Yang et al., 2014; Zhang, 2008) and aligned with PYMOL (version 2.0, Schrodinger LLC) to an IgM cryoglobulin Fab crystal structure (PDB 2AGJ) (Ramsland et al., 2006) to form the complete DH1017.Fab homology model. The $\mathrm{C}_{\alpha}$ backbones of all structures were fit in the cryo-EM map using Chimera (Pettersen et al., 2004) fit-to-map function. The position of the Fab domains was further refined with Coot (Emsley, P 2010). Residues of the $E$ ectodomain $C_{\alpha}$ backbone within $6 \AA$ of the Fab fragment $C_{\alpha}$ backbone were identified with PYMOL. These residues are defined as the Fab footprint and mapped to the surface of the virus particle with RIVEM (Xiao and Rossmann, 2007). The binding of a human IgM pentamer to the virus surface at the five-fold icosahedral axis was modeled. The solution structure of an $\operatorname{lgM}$ pentamer (PDB 2CRJ) (Perkins et al., 1991) and the homology model of DH1017.Fab from this paper were used to build the model. The $\mathrm{Fc}$ domains $\mathrm{C} \mu 4, \mathrm{C} \mu 3$, and $\mathrm{C} \mu 2$ of PDB $2 \mathrm{CRJ}$ were modeled to similar positions of $\mathrm{C} \mu 4$ (PDB 4JVW), C $\mu 3$ (PDB 4BA8), and C 42 (4JVU) domains fit to the 25A tomogram of an IgM pentamer bound to the surface of an artificial liposome (Müller et al., 2013; Sharp et al., 2019). One Fab domain from each monomer of the pentamer structure PDB 2CRJ were fit to the density map after being aligned manually to the fitted DH1017.Fab structure. 
Assessing protection in ZIKV mouse model. Animal husbandry and experiments were performed under the approval of the University of North Carolina at Chapel Hill Institutional Animal Care and Use Committee. Five-week-old male Ifnar $1^{-1-}$ mice were inoculated with a lethal dose of ZIKV strain H/PF/2013 (1 x 103 FFU) subcutaneously in the footpad on day 0 (Lazear et al., 2016). On days -1 and $+1,100 \mu \mathrm{g}$ of antibody was delivered intravenously via the retro-orbital route. Serum was collected every two days for 11 days to monitor viremia by qRT-PCR and survival was monitored for 15 days. Animals that lost $\geq 30 \%$ of their starting weight or that exhibited severe disease signs were euthanized.

Measuring viral burden in mice. RNA from the serum of ZIKV-infected mice was extracted with the Qiagen viral RNA minikit. ZIKV RNA was quantified by TaqMan one-step qRT-PCR using a CFX96 Touch real-time PCR detection system (Bio-Rad). Genome copies per $\mathrm{mL}$ of serum on a $\log _{10}$ scale was determined by comparison with a standard curve generated by using serial 10fold dilutions of a ZIKV plasmid and previously reported primers: forward primer CCGCTGCCCAACACAAG, reverse primer CCACTAACGTTCTTTTGCAGACAT, and probe 5'FAM (6-carboxyfluorescein)-AGCCTACCT-ZEN-TGACAAGCAATCAGACACTCAA-3'IABkFQ (Integrated DNA Technologies) (Carbaugh et al., 2019).

Reactivity to autoantigens. ELISA was performed in 384-well plates (Corning) as previously described (Bonsignori et al., 2011). Briefly, plates were coated overnight at $4^{\circ} \mathrm{C}$ with $15 \mu \mathrm{l}$ purified proteins at optimized concentrations in 0.1M Sodium Bicarbonate: DNA (Worthington, LS002105) at $5 \mu \mathrm{g} / \mathrm{mL}$, Centromere B (Prospec, PRO-390) at $0.15 \mu \mathrm{g} / \mathrm{mL}$, Histone (Sigma, H9250) at $0.2 \mu \mathrm{g} / \mathrm{mL}$, Jo-1 (Immunovision, JO1-3000) at 0.05 units/well, RnP/Sm (Immunovision, SRC-3000) at 0.2 units/well, Scl-70 (Immunovision, SCL-3000) at 0.4 units/well, Sm (Immunovision, SMA3000 ) at 0.1 units/well, SSA (Immunovision, SSA-3000) at 0.2 units/well, and SSB (Immunovision, SSB-3000) at 0.1 units/well. Subsequently, plates were blocked (50 $\mu$ L/well) with assay diluent (PBS containing 4\% [w/v] whey protein, 15\% normal goat serum, 0.5\% Tween 20) for 2 hours at room temperature. For DNA, plates were pre-coated with Poly-L-Lysine (Sigma, P6282) at $2 \mu \mathrm{g} / \mathrm{mL}$ in PBS overnight at $4^{\circ} \mathrm{C}$, and the assay diluent was PBS containing $2 \%[\mathrm{w} / \mathrm{v}$ ] bovine serum albumin and $0.05 \%$ Tween-20. Monoclonal antibodies were tested using 3-fold serial dilutions starting at $10 \mu \mathrm{g} / \mathrm{ml}$. $10 \mu \mathrm{l}$ of primary antibodies were added to each well and incubated for 1 hour at room temperature. The following positive control antibodies from Immunovision were all tested at a 1:25 starting dilution with 3-fold serial dilutions: Anti-Centromere B (HCT-0100), Anti-single stranded DNA (HSS-0100), Anti-Histone (HIS-0100), Anti-Jo 1 (HJO-0100), Anti-SRC (HRN-0100), Anti-Scl 70 (HSC-0100), Anti-Sm (HSM-0100), Anti-SSA (HSA-0100), and Anti-SSB

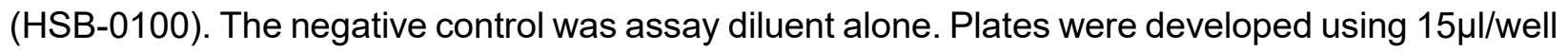
of combination of horseradish peroxidase-conjugated antibodies in assay diluent comprising) goat anti-human IgG (Jackson ImmunoResearch Laboratories,109-035-098) at 1:10,000 dilution; 2) goat anti-human IgM (Jackson ImmunoResearch Laboratories,109-035-129) at 1:10,000 dilution; 3) goat anti-human $\mathrm{H}+\mathrm{L}$ (Promega, W403B) at 1:3,000 dilution. After a 1 hour incubation, plates were developed with $20 \mu \mathrm{l} /$ well of SureBlue Reserve TMB substrate (KPL) and stopped by $20 \mu \mathrm{l} /$ well Stop Solution (KPL) after five minutes. Optical density (OD) was detected at $450 \mathrm{~nm}$ (Perkin Elmer, Victor). 
bioRxiv preprint doi: https://doi.org/10.1101/2021.11.23.469700; this version posted November 24, 2021. The copyright holder for this preprint (which was not certified by peer review) is the author/funder, who has granted bioRxiv a license to display the preprint in perpetuity. It is made available under aCC-BY 4.0 International license.

901 HEp-2 Cell Staining. Indirect immunofluorescence (Zeuss Scientific) binding of DH1017 mAbs 902 to HEp-2 cells was performed as previously described (Bonsignori et al., 2014). IgG1 mAbs 2F5 903 and 17B were used as positive and negative controls, respectively. All mAbs were tested at $90425 \mathrm{ug} / \mathrm{ml}$ and $50 \mathrm{ug} / \mathrm{mL}$. Images were acquired for 8 seconds with a 40x objective. 


\section{References}

Abbink, P., Larocca, R.A., De La Barrera, R.A., Bricault, C.A., Moseley, E.T., Boyd, M., Kirilova, M., Li, Z., Ng'ang'a, D., Nanayakkara, O., et al. (2016). Protective efficacy of multiple vaccine platforms against Zika virus challenge in rhesus monkeys. Science (80-. ). 353, 1129-1132.

Bonsignori, M., Hwang, K.-K., Chen, X., Tsao, C.-Y., Morris, L., Gray, E., Marshall, D.J., Crump, J.A., Kapiga, S.H., Sam, N.E., et al. (2011). Analysis of a Clonal Lineage of HIV-1 Envelope V2/V3 Conformational Epitope-Specific Broadly Neutralizing Antibodies and Their Inferred Unmutated Common Ancestors. J. Virol. 85, 9998-10009.

Bonsignori, M., Wiehe, K., Grimm, S.K., Lynch, R., Yang, G., Kozink, D.M., Perrin, F., Cooper, A.J., Hwang, K.K., Chen, X., et al. (2014). An autoreactive antibody from an SLE/HIV-1 individual broadly neutralizes HIV-1. J. Clin. Invest. 124, 1835-1843.

Bonsignori, M., Zhou, T., Sheng, Z., Chen, L., Gao, F., Joyce, M.G., Ozorowski, G., Chuang, G.Y., Schramm, C.A., Wiehe, K., et al. (2016). Maturation Pathway from Germline to Broad HIV1 Neutralizer of a CD4-Mimic Antibody. Cell 165, 449-463.

Bonsignori, M., Scott, E., Wiehe, K., Easterhoff, D., Alam, S.M., Hwang, K.K., Cooper, M., Xia, S.M., Zhang, R., Montefiori, D.C., et al. (2018). Inference of the HIV-1 VRC01 Antibody Lineage Unmutated Common Ancestor Reveals Alternative Pathways to Overcome a Key Glycan Barrier. Immunity 49, 1162-1174.e8.

Calvert, A.E., Horiuchi, K., Boroughs, K.L., Ong, Y.T., Anderson, K.M., Biggerstaff, B.J., Stone, M., Simmons, G., Busch, M.P., and Huang, C.Y.-H. (2021). The Specificity of the Persistent IgM Neutralizing Antibody Response in Zika Viral Infections Among Individuals with Prior Dengue Virus Exposure. J. Clin. Microbiol.

Campos, M.C., Dombrowski, J.G., Phelan, J., Marinho, C.R.F., Hibberd, M., Clark, T.G., and Campino, S. (2018). Zika might not be acting alone: Using an ecological study approach to investigate potential co-acting risk factors for an unusual pattern of microcephaly in Brazil. PLoS One 13, e0201452.

Carbaugh, D.L., Baric, R.S., and Lazear, H.M. (2019). Envelope Protein Glycosylation Mediates Zika Virus Pathogenesis. J. Virol. 93.

Chan, C.Y.Y., Low, J.Z.H., Gan, E.S., Ong, E.Z., Zhang, S.L.-X., Tan, H.C., Chai, X., Ghosh, S., Ooi, E.E., and Chan, K.R. (2019). Antibody-Dependent Dengue Virus Entry Modulates Cell Intrinsic Responses for Enhanced Infection. MSphere 4, 528-547.

Chan, K.R., Zhang, S.L.-X., Tan, H.C., Chan, Y.K., Chow, A., Lim, A.P.C., Vasudevan, S.G., Hanson, B.J., and Ooi, E.E. (2011). Ligation of Fc gamma receptor IIB inhibits antibodydependent enhancement of dengue virus infection. Proc. Natl. Acad. Sci. 108, 12479-12484.

Chan, K.R., Ong, E.Z., Tan, H.C., Zhang, S.L.-X., Zhang, Q., Tang, K.F., Kaliaperumal, N., Lim, A.P.C., Hibberd, M.L., Chan, S.H., et al. (2014). Leukocyte immunoglobulin-like receptor B1 is critical for antibody-dependent dengue. Proc. Natl. Acad. Sci. U. S. A. 111, 2722-2727.

Chan, K.R., Ong, E.Z., Mok, D.Z.L., and Ooi, E.E. (2015). Fc receptors and their influence on efficacy of therapeutic antibodies for treatment of viral diseases. Expert Rev. Anti. Infect. Ther. 13, 1351-1360.

Christiansen, J.S., Andersen, A.R., Osther, K., Peitersen, B., Bach-Mortensen, N., and Lebech, P.E. (1976). THE RELATIONSHIP BETWEEN PREGNANCY, HCS AND B LYMPHOCYTES. 
Acta Pathol. Microbiol. Scand. Sect. C Immunol. 84 C, 313-318.

Chua, C.-L., Sam, I.-C., Chiam, C.-W., and Chan, Y.-F. (2017). The neutralizing role of IgM during early Chikungunya virus infection. PLoS One 12, e0171989.

Collins, M.H., Tu, H.A., Gimblet-Ochieng, C., Liou, G.J.A., Jadi, R.S., Metz, S.W., Thomas, A., McElvany, B.D., Davidson, E., Doranz, B.J., et al. (2019). Human antibody response to Zika targets type-specific quaternary structure epitopes. JCl Insight 4.

Craig, A.M., Hughes, B.L., and Swamy, G.K. (2021). Coronavirus disease 2019 vaccines in pregnancy. Am. J. Obstet. Gynecol. MFM 3, 100295.

Diamond, M.S., Sitati, E.M., Friend, L.D., Higgs, S., Shrestha, B., and Engle, M. (2003). A Critical Role for Induced IgM in the Protection against West Nile Virus Infection. J. Exp. Med. 198, 1853-1862.

Gasser, R., Cloutier, M., Prévost, J., Fink, C., Ducas, É., Dussault, N., Landry, P., Tremblay, T., Laforce-Lavoie, A., Lewin, A., et al. (2020). Major role of IgM in the neutralizing activity of convalescent plasma against SARS-CoV-2. BioRxiv 2020.10.09.333278.

Gibney, K.B., Edupuganti, S., Panella, A.J., Kosoy, O.I., Delorey, M.J., Lanciotti, R.S., Mulligan, M.J., Fischer, M., and Staples, J.E. (2012). Detection of anti-yellow fever virus immunoglobulin $\mathrm{M}$ antibodies at 3-4 years following yellow fever vaccination. Am. J. Trop. Med. Hyg. 87, 11121115.

Gilchuk, P., Bombardi, R.G., Erasmus, J.H., Tan, Q., Nargi, R., Soto, C., Abbink, P., Suscovich, T.J., Durnell, L.A., Khandhar, A., et al. (2020). Integrated pipeline for the accelerated discovery of antiviral antibody therapeutics. Nat. Biomed. Eng. 4, 1030-1043.

Gomes, M.F., De La Fuente-Núñez, V., Saxena, A., and Kuesel, A.C. (2017). Protected to death: Systematic exclusion of pregnant women from Ebola virus disease trials. Reprod. Health 14.

Grant, T., Rohou, A., and Grigorieff, N. (2018). CisTEM, user-friendly software for single-particle image processing. Elife 7.

Griffin, I., Martin, S.W., Fischer, M., Chambers, T. V., Kosoy, O.L., Goldberg, C., Falise, A., Villamil, V., Ponomareva, O., Gillis, L.D., et al. (2019). Zika virus IGM 25 months after symptom onset, Miami-Dade County, Florida, USA. Emerg. Infect. Dis. 25, 2264-2265.

Guo, F., and Jiang, W. (2014). Single particle cryo-electron microscopy and 3-D reconstruction of viruses. Methods Mol. Biol. 1117, 401-443.

Halstead, S.B. (1988). Pathogenesis of dengue: Challenges to molecular biology. Science (80-. ). $239,476-481$.

Halstead, S.B., and O'Rourke, E.J. (1977). Antibody-enhanced dengue virus infection in primate leukocytes [21]. Nature 265, 739-741.

Hasan, S.S., Miller, A., Sapparapu, G., Fernandez, E., Klose, T., Long, F., Fokine, A., Porta, J.C., Jiang, W., Diamond, M.S., et al. (2017a). A human antibody against Zika virus crosslinks the $\mathrm{E}$ protein to prevent infection. Nat. Commun. 8, 14722.

Hasan, S.S., Miller, A., Sapparapu, G., Fernandez, E., Klose, T., Long, F., Fokine, A., Porta, J.C., Jiang, W., Diamond, M.S., et al. (2017b). A human antibody against Zika virus crosslinks the $\mathrm{E}$ protein to prevent infection. Nat. Commun. 8, 1-6. 
Heath, E., Begue-Pastor, N., Chaganti, S., Croom-Carter, D., Shannon-Lowe, C., Kube, D., Feederle, R., Delecluse, H.-J., Rickinson, A.B., and Bell, A.I. (2012). Epstein-Barr Virus Infection of Naïve B Cells In Vitro Frequently Selects Clones with Mutated Immunoglobulin Genotypes: Implications for Virus Biology. PLOS Pathog. 8, e1002697.

Hensel, F., Timmermann, W., Von Rahden, B.H.A., Rosenwald, A., Brändlein, S., and Illert, B. (2014). Ten-year follow-up of a prospective trial for the targeted therapy of gastric cancer with the human monoclonal antibody PAT-SC1. Oncol. Rep. 31, 1059-1066.

Hombach, J., Solomon, T., Kurane, I., Jacobson, J., and Wood, D. (2005). Report on a WHO consultation on immunological endpoints for evaluation of new Japanese encephalitis vaccines, WHO, Geneva, 2-3 September, 2004. Vaccine 23, 5205-5211.

Katzelnick, L.C., Harris, E., Baric, R., Coller, B.A., Coloma, J., Crowe, J.E., Cummings, D.A.T., Dean, H., De Silva, A., Diamond, M.S., et al. (2017). Immune correlates of protection for dengue: State of the art and research Agenda. In Vaccine, (Elsevier Ltd), pp. 4659-4669.

Keyt, B.A., Baliga, R., Sinclair, A.M., Carroll, S.F., and Peterson, M.S. (2020). Structure, Function, and Therapeutic Use of IgM Antibodies. Antibodies 9, 53.

King, H.W., Orban, N., Riches, J.C., Clear, A.J., Warnes, G., Teichmann, S.A., and James, L.K. (2021). Single-cell analysis of human B cell maturation predicts how antibody class switching shapes selection dynamics. Sci. Immunol. 6.

Kreil, T.R., Burger, I., Bachmann, M., Fraiss, S., and Eibl, M.M. (1997). Antibodies protect mice against challenge with tick-borne encephalitis virus (TBEV)-infected macrophages. Clin. Exp. Immunol. 110, 358-361.

Kwek, S. Sen, Watanabe, S., Chan, K.R., Ong, E.Z., Tan, H.C., Ng, W.C., Nguyen, M.T.X., Gan, E.S., Zhang, S.L., Chan, K.W.K., et al. (2018). A systematic approach to the development of a safe live attenuated Zika vaccine. Nat. Commun. 9, 1031.

Larocca, R.A., Abbink, P., Peron, J.P.S., Zanotto, P.M.D.A., lampietro, M.J., Badamchi-Zadeh, A., Boyd, M., Ng'ang'a, D., Kirilova, M., Nityanandam, R., et al. (2016). Vaccine protection against Zika virus from Brazil. Nature 536, 474-478.

Lazear, H.M., Govero, J., Smith, A.M., Platt, D.J., Fernandez, E., Miner, J.J., and Diamond, M.S. (2016). A Mouse Model of Zika Virus Pathogenesis. Cell Host Microbe 19, 720-730.

Lessler, J., Ott, C.T., Carcelen, A.C., Konikoff, J.M., Williamson, J., Bi, Q., Kucirka, L.M., Cummings, D.A.T., Reich, N.G., and Chaisson, L.H. (2016). Times to key events in Zika virus infection and implications for blood donation: A systematic review. Bull. World Health Organ. 94, 841-849.

Liao, H.-X., Levesque, M.C., Nagel, A., Dixon, A., Zhang, R., Walter, E., Parks, R., Whitesides, J., Marshall, D.J., Hwang, K.-K., et al. (2009). High-throughput isolation of immunoglobulin genes from single human $B$ cells and expression as monoclonal antibodies. J Virol Methods 158, 171-179.

Lima, J., Martins, C., Leandro, M.J., Nunes, G., Sousa, M.J., Branco, J.C., and Borrego, L.M. (2016). Characterization of B cells in healthy pregnant women from late pregnancy to postpartum: A prospective observational study. BMC Pregnancy Childbirth 16, 139.

Lobo, E.D., Hansen, R.J., and Balthasar, J.P. (2004). Antibody pharmacokinetics and pharmacodynamics. J. Pharm. Sci. 93, 2645-2668. 
1030

1031

1032

1033

1034

1035

1036

1037

1038

1039

1040

1041

1042

1043

1044

1045

1046

1047

1048

1049

1050

1051

1052

1053

1054

1055

1056

1057

1058

1059

1060

1061

1062

1063

1064

1065

1066

1067

1068

1069

1070

1071

Long, F., Doyle, M., Fernandez, E., Miller, A.S., Klose, T., Sevvana, M., Bryan, A., Davidson, E., Doranz, B.J., Kuhn, R.J., et al. (2019). Structural basis of a potent human monoclonal antibody against Zika virus targeting a quaternary epitope. Proc. Natl. Acad. Sci. U. S. A. 116, 15911596.

Maciejewski, S., Ruckwardt, T.J., Morabito, K.M., Foreman, B.M., Burgomaster, K.E., Gordon, D.N., Pelc, R.S., DeMaso, C.R., Ko, S.Y., Fisher, B.E., et al. (2020). Distinct neutralizing antibody correlates of protection among related Zika virus vaccines identify a role for antibody quality. Sci. Transl. Med. 12, 9066.

Malafa, S., Medits, I., Aberle, J.H., Aberle, S.W., Haslwanter, D., Tsouchnikas, G., Wölfel, S., Huber, K.L., Percivalle, E., Cherpillod, P., et al. (2020). Impact of flavivirus vaccine-induced immunity on primary Zika virus antibody response in humans. PLoS Negl. Trop. Dis. 14, e0008034.

Mason, R.A., Tauraso, N.M., Spertzel, R.O., and Ginn, R.K. (1973). Yellow fever vaccine: direct challenge of monkeys given graded doses of 17D vaccine. Appl. Microbiol. 25, 539-544.

Mehlhop, E., Nelson, S., Jost, C.A., Gorlatov, S., Johnson, S., Fremont, D.H., Diamond, M.S., and Pierson, T.C. (2009). Complement Protein C1q Reduces the Stoichiometric Threshold for Antibody-Mediated Neutralization of West Nile Virus. Cell Host Microbe 6, 381-391.

Metz, S.W., Thomas, A., Brackbill, A., Forsberg, J., Miley, M.J., Lopez, C.A., Lazear, H.M., Tian, S., and de Silva, A.M. (2019). Oligomeric state of the ZIKV E protein defines protective immune responses. Nat. Commun. 10,1-7.

Monath, T. (1971). Neutralizing antibody responses in the major immunoglobulin classes to Yellow Fever 17D vaccination of humans. Am. J. Epidemiol. 93, 122-129.

Morabito, K.M., and Graham, B.S. (2017). Zika Virus Vaccine Development. J. Infect. Dis. 216, S957-S963.

Mrozek-Gorska, P., Buschle, A., Pich, D., Schwarzmayr, T., Fechtner, R., Scialdone, A., and Hammerschmidt, W. (2019). Epstein-Barr virus reprograms human B lymphocytes immediately in the prelatent phase of infection. Proc. Natl. Acad. Sci. 116, 16046-16055.

Mukherjee, S., Sirohi, D., Dowd, K.A., Chen, Z., Diamond, M.S., Kuhn, R.J., and Pierson, T.C. (2016). Enhancing dengue virus maturation using a stable furin over-expressing cell line. Virology 497, 33-40.

Müller, R., Gräwert, M.A., Kern, T., Madl, T., Peschek, J., Sattler, M., Groll, M., and Buchner, J. (2013). High-resolution structures of the IgM Fc domains reveal principles of its hexamer formation. Proc. Natl. Acad. Sci. U. S. A. 110, 10183-10188.

Nguyen, T.G., Ward, C.M., and Morris, J.M. (2013). To B or not to B cells-mediate a healthy start to life. Clin. Exp. Immunol. 171, 124-134.

Nielsen-Saines, K., Brasil, P., Kerin, T., Vasconcelos, Z., Gabaglia, C.R., Damasceno, L., Pone, M., Abreu de Carvalho, L.M., Pone, S.M., Zin, A.A., et al. (2019). Delayed childhood neurodevelopment and neurosensory alterations in the second year of life in a prospective cohort of ZIKV-exposed children. Nat. Med. 25, 1213-1217.

Paz-Bailey, G., Rosenberg, E.S., Doyle, K., Munoz-Jordan, J., Santiago, G.A., Klein, L., PerezPadilla, J., Medina, F.A., Waterman, S.H., Adams, L.E., et al. (2018). Persistence of Zika Virus in Body Fluids - Final Report. N. Engl. J. Med. 379, 1234-1243. 
1072

1073

1074

1075

1076

1077

1078

1079

1080

1081

1082

1083

1084

1085

1086

1087

1088

1089

1090

1091

1092

1093

1094

1095

1096

1097

1098

1099

1100

1101

1102

1103

1104

1105

1106

1107

1108

1109

1110

1111

1112

1113

Perkins, S.J., Nealis, A.S., Sutton, B.J., and Feinstein, A. (1991). Solution structure of human and mouse immunoglobulin $\mathrm{M}$ by synchrotron $\mathrm{X}$-ray scattering and molecular graphics modelling. A possible mechanism for complement activation. J. Mol. Biol. 221, 1345-1366.

Pettersen, E.F., Goddard, T.D., Huang, C.C., Couch, G.S., Greenblatt, D.M., Meng, E.C., and Ferrin, T.E. (2004). UCSF Chimera - A visualization system for exploratory research and analysis. J. Comput. Chem. 25, 1605-1612.

Premkumar, L., Collins, M., Graham, S., Liou, G.-J.A., Lopez, C.A., Jadi, R., Balmaseda, A., Brackbill, J.A., Dietze, R., Camacho, E., et al. (2017). Development of Envelope Protein Antigens To Serologically Differentiate Zika Virus Infection from Dengue Virus Infection. J. Clin. Microbiol. 56.

Ramsland, P.A., Terzyan, S.S., Cloud, G., Bourne, C.R., Farrugia, W., Tribbick, G., Geysen, H.M., Moomaw, C.R., Slaughter, C.A., and Edmundson, A.B. (2006). Crystal structure of a glycosylated Fab from an IgM cryoglobulin with properties of a natural proteolytic antibody. Biochem. J. 395, 473-481.

Rasche, L., Duell, J., Castro, I.C., Dubljevic, V., Chatterjee, M., Knop, S., Hensel, F., Rosenwald, A., Einsele, H., Topp, M.S., et al. (2015). GRP78-directed immunotherapy in relapsed or refractory multiple myeloma - results from a phase 1 trial with the monoclonal immunoglobulin M antibody PAT-SM6. Haematologica 100, 377-384.

Ravichandran, S., Hahn, M., Belaunzarán-Zamudio, P.F., Ramos-Castañeda, J., NájeraCancino, G., Caballero-Sosa, S., Navarro-Fuentes, K.R., Ruiz-Palacios, G., Golding, H., Beigel, J.H., et al. (2019). Differential human antibody repertoires following Zika infection and the implications for serodiagnostics and disease outcome. Nat. Commun. 10, 1-14.

Reynolds, M.R., Jones, A.M., Petersen, E.E., Lee, E.H., Rice, M.E., Bingham, A., Ellington, S.R., Evert, N., Reagan-Steiner, S., Oduyebo, T., et al. (2017). Vital Signs: Update on Zika Virus-Associated Birth Defects and Evaluation of All U.S. Infants with Congenital Zika Virus Exposure - U.S. Zika Pregnancy Registry, 2016. MMWR. Morb. Mortal. Wkly. Rep. 66, 366373.

Richner, J.M., Jagger, B.W., Shan, C., Fontes, C.R., Dowd, K.A., Cao, B., Himansu, S., Caine, E.A., Nunes, B.T.D., Medeiros, D.B.A., et al. (2017). Vaccine Mediated Protection Against Zika Virus-Induced Congenital Disease. Cell 170, 273-283.e12.

Robbiani, D.F., Bozzacco, L., Keeffe, J.R., Khouri, R., Olsen, P.C., Gazumyan, A., SchaeferBabajew, D., Avila-Rios, S., Nogueira, L., Patel, R., et al. (2017). Recurrent Potent Human Neutralizing Antibodies to Zika Virus in Brazil and Mexico. Cell 169, 597-609.e11.

Rogers, T.F., Goodwin, E.C., Briney, B., Sok, D., Beutler, N., Strubel, A., Nedellec, R., Le, K., Brown, M.E., Burton, D.R., et al. (2017). Zika virus activates de novo and cross-reactive memory B cell responses in dengue-experienced donors. Sci. Immunol. 2.

Rohou, A., and Grigorieff, N. (2015). CTFFIND4: Fast and accurate defocus estimation from electron micrographs. J. Struct. Biol. 192, 216-221.

Van Rompay, K.K.A., Coffey, L.L., Kapoor, T., Gazumyan, A., Keesler, R.I., Jurado, A., Peace, A., Agudelo, M., Watanabe, J., Usachenko, J., et al. (2020). A combination of two human monoclonal antibodies limits fetal damage by Zika virus in macaques. Proc. Natl. Acad. Sci. 117, 202000414. 
Rosenthal, P.B., and Henderson, R. (2003). Optimal determination of particle orientation, absolute hand, and contrast loss in single-particle electron cryomicroscopy. J. Mol. Biol. 333, 721-745.

1117 Rouvinski, A., Guardado-Calvo, P., Barba-Spaeth, G., Duquerroy, S., Vaney, M.C., Kikuti, C.M., Navarro Sanchez, M.E., Dejnirattisai, W., Wongwiwat, W., Haouz, A., et al. (2015). Recognition determinants of broadly neutralizing human antibodies against dengue viruses. Nature 520 , 109-113.

Roy, A., Kucukural, A., and Zhang, Y. (2010). I-TASSER: A unified platform for automated protein structure and function prediction. Nat. Protoc. 5, 725-738.

1123 Sapparapu, G., Fernandez, E., Kose, N., Bin Cao, Fox, J.M., Bombardi, R.G., Zhao, H., Nelson, C.A., Bryan, A.L., Barnes, T., et al. (2016). Neutralizing human antibodies prevent Zika virus replication and fetal disease in mice. Nature 540, 443-447.

1126 Scheres, S.H.. (2016). Methods in Enzymology, Vol. 579 (Cambridge, MA: Academic Press).

Scheres, S.H.W., Valle, M., and Carazo, J.M. (2005). Fast maximum-likelihood refinement of electron microscopy images. Bioinformatics 21.

1129 Sevvana, M., Long, F., Miller, A.S., Klose, T., Buda, G., Sun, L., Kuhn, R.J., and Rossmann, M.G. (2018). Refinement and Analysis of the Mature Zika Virus Cryo-EM Structure at $3.1 \AA$ Resolution. Structure 26, 1169-1177.e3.

Sharp, T.H., Boyle, A.L., Diebolder, C.A., Kros, A., Koster, A.J., and Gros, P. (2019). Insights into IgM-mediated complement activation based on in situ structures of IgM-C1-C4b. Proc. Natl. Acad. Sci. U. S. A. 116, 11900-11905.

Sigworth, F.J. (1998). A maximum-likelihood approach to single-particle image refinement. J. Struct. Biol. 122, 328-339.

1137 Sigworth, F.J. (2004). Classical detection theory and the cryo-EM particle selection problem. In Journal of Structural Biology, (J Struct Biol), pp. 111-122.

1139 Singh, T., Lopez, C.A., Giuberti, C., Dennis, M.L., Itell, H.L., Heimsath, H.J., Webster, H.S., 1140 Roark, H.K., Merçon de Vargas, P.R., Hall, A., et al. (2019). Efficient transplacental IgG transfer in women infected with Zika virus during pregnancy. PLoS Negl. Trop. Dis. 13, e0007648.

Smit, J.M., Moesker, B., Rodenhuis-Zybert, I., and Wilschut, J. (2011). Flavivirus cell entry and membrane fusion. Viruses 3, 160-171.

1144 Smith, S.A., de Alwis, A.R., Kose, N., Harris, E., Ibarra, K.D., Kahle, K.M., Pfaf, J.M., Xiang, X., Doranz, B.J., de Silva, A.M., et al. (2013). The potent and broadly neutralizing human dengue virus-specific monoclonal antibody $1 \mathrm{C} 19$ reveals a unique cross-reactive epitope on the bc loop of domain II of the envelope protein. MBio 4.

Smith, S.A., Silva, L.A., Fox, J.M., Flyak, A.I., Kose, N., Sapparapu, G., Khomandiak, S., Ashbrook, A.W., Kahle, K.M., Fong, R.H., et al. (2015). Isolation and characterization of broad and ultrapotent human monoclonal antibodies with therapeutic activity against chikungunya virus. Cell Host Microbe 18, 86-95.

1152 Stettler, K., Beltramello, M., Espinosa, D.A., Graham, V., Cassotta, A., Bianchi, S., Vanzetta, F., 
Stone, M., Bakkour, S., Lanteri, M.C., Brambilla, D., Simmons, G., Bruhn, R., Kaidarova, Z., Lee, T.H., Orlando Alsina, J., Williamson, P.C., et al. (2020). Zika virus RNA and IgM persistence in blood compartments and body fluids: a prospective observational study. Lancet Infect. Dis. 20, 1446-1456.

Suloway, C., Pulokas, J., Fellmann, D., Cheng, A., Guerra, F., Quispe, J., Stagg, S., Potter, C.S., and Carragher, B. (2005). Automated molecular microscopy: The new Leginon system. J. Struct. Biol. 151, 41-60.

Swanstrom, J.A., Plante, J.A., Plante, K.S., Young, E.F., McGowan, E., Gallichotte, E.N., Widman, D.G., Heise, M.T., de Silva, A.M., and Baric, R.S. (2016). Dengue virus envelope virus. MBio 7.

Taylor, H.P., and Dimmock, N.J. (1985). Mechanisms of Neutralization of Influenza Virus by IgM. J. Gen. Virol 66, 903-907.

Tonnerre, P., Melgaço, J.G., Torres-Cornejo, A., Pinto, M.A., Yue, C., Blümel, J., de Sousa, P.S.F., de Mello, V. da M., Moran, J., de Filippis, A.M.B., et al. (2020). Evolution of the innate and adaptive immune response in women with acute Zika virus infection. Nat. Microbiol. 5, 7683.

Wang, J., Bardelli, M., Espinosa, D.A., Pedotti, M., Ng, T.S., Bianchi, S., Simonelli, L., Lim, E.X.Y., Foglierini, M., Zatta, F., et al. (2017). A Human Bi-specific Antibody against Zika Virus with High Therapeutic Potential. Cell 171, 229-241.e15.

Wec, A.Z., Haslwanter, D., Abdiche, Y.N., Shehata, L., Pedreño-Lopez, N., Moyer, C.L., Bornholdt, Z.A., Lilov, A., Nett, J.H., Jangra, R.K., et al. (2020). Longitudinal dynamics of the human B cell response to the yellow fever 17D vaccine. Proc. Natl. Acad. Sci. U. S. A. 117, 6675-6685.

1179 Wiersma, E.J., Collins, C., Fazel, S., and Shulman, M.J. (1998). Structural and functional

Xiao, C., and Rossmann, M.G. (2007). Interpretation of electron density with stereographic roadmap projections. J. Struct. Biol. 158, 182-187.

Yaari, G., Vander Heiden, J., Uduman, M., Gadala-Maria, D., Gupta, N., Stern, J.N.H., O'Connor, K., Hafler, D., Laserson, U., Vigneault, F., et al. (2013). Models of Somatic Hypermutation Targeting and Substitution Based on Synonymous Mutations from HighThroughput Immunoglobulin Sequencing Data. Front. Immunol. 0, 358.

1189 Zhang, Y. (2008). I-TASSER server for protein 3D structure prediction. BMC Bioinformatics 9.

1190 Zhang, S.L.X., Tan, H.C., Hanson, B.J., and Ooi, E.E. (2010). A simple method for Alexa Fluor 1191 dye labelling of dengue virus. J. Virol. Methods 167, 172-177. 
bioRxiv preprint doi: https://doi.org/10.1101/2021.11.23.469700; this version posted November 24, 2021. The copyright holder for this preprint (which was not certified by peer review) is the author/funder, who has granted bioRxiv a license to display the preprint in perpetuity. It is made available under aCC-BY 4.0 International license.

1196 Nelson, C.A., Pierson, T.C., Diamond, M.S., et al. (2016). Structural Basis of Zika Virus-Specific 1197 Antibody Protection. Cell 166, 1016-1027.

1198 Zheng, S.Q., Palovcak, E., Armache, J.P., Verba, K.A., Cheng, Y., and Agard, D.A. (2017).

1199 MotionCor2: Anisotropic correction of beam-induced motion for improved cryo-electron

1200 microscopy. Nat. Methods 14, 331-332.

1201 
bioRxiv preprint doi: https://doi.org/10.1101/2021.11.23.469700; this version posted November 24, 2021. The copyright holder for this preprint (which was not certified by peer review) is the author/funder, who has granted bioRxiv a license to display the preprint in perpetuity. It is made available under aCC-BY 4.0 International license.

Table 1. Immunogenetics of monoclonal antibodies isolated from B-LCLs. See also Figure S1 and Table S2.

\begin{tabular}{|c|c|c|c|c|c|c|c|c|c|c|c|c|}
\hline Antibody ID & Source* & $\mathrm{V}_{\mathrm{H}}$ & $\mathrm{D}$ & $J_{H}$ & $\begin{array}{c}\begin{array}{c}V_{H} \text { mutation } \\
\text { frequency }(\%)\end{array} \\
\end{array}$ & $\begin{array}{c}\text { CDRH3 } \\
\text { length (aa) }\end{array}$ & Isotype & $\mathrm{k} / \mathrm{l}$ & $\mathrm{V}_{\mathrm{L}}$ & $J_{L}$ & $\begin{array}{c}V_{L} \text { mutation } \\
\text { frequency }(\%)\end{array}$ & $\begin{array}{l}\text { CDRL3 length } \\
\text { (aa) } \\
\end{array}$ \\
\hline 119-4-D6.lgG & UBC & $3-64$ & $2-2$ & 6 & 9.4 & 13 & G1 & lambda & $3-21$ & 1 & 7.97 & 11 \\
\hline 119-5-C5.IgG & UBC & $3-21$ & $6-13$ & 6 & 3.1 & 22 & G1 & kappa & $3-11$ & 4 & 1.52 & 9 \\
\hline 123-3-G2.IgG & MBC & $3-30-3$ & $3-3$ & 4 & 3.1 & 12 & G1 & kappa & $2-30$ & 4 & 3.6 & 9 \\
\hline 124-4-C8.IgG & MBC & $3-30$ & $3-16$ & 6 & 9.3 & 22 & G1 & kappa & $2-28$ & 4 & 3.0 & 10 \\
\hline 126-1-D11.lgG & MBC & $3-48$ & $4-17$ & 6 & 4.5 & 16 & G1 & kappa & $1-39$ & 2 & 3.8 & 9 \\
\hline
\end{tabular}

* UBC: unfractionated B cells; MBC: memory B cells 


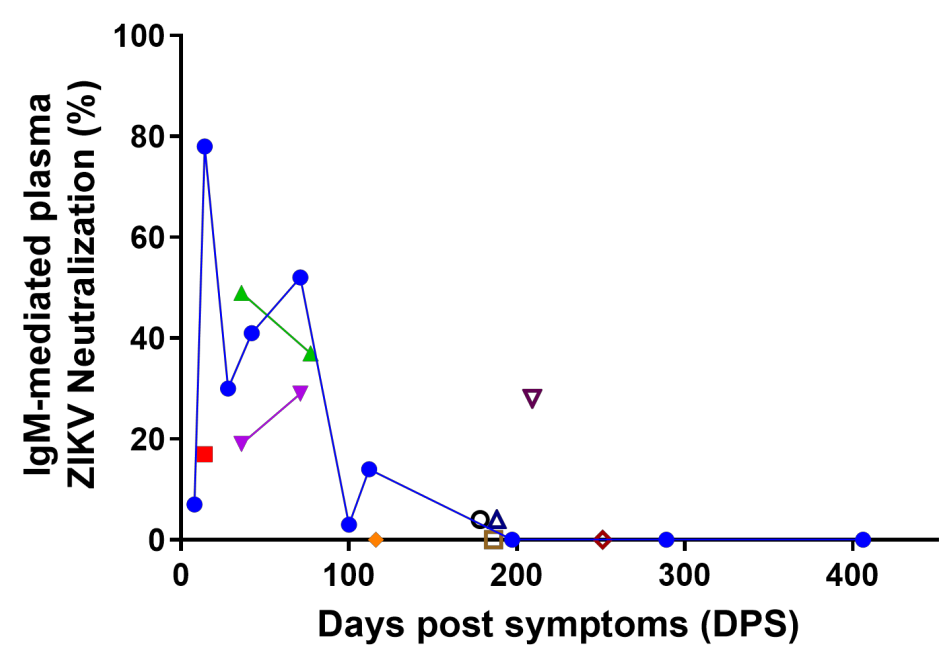

$$
\begin{aligned}
& \text { Primary } \\
& \text { Infection } \\
& \text { 曰 P24 } \\
& \text { - P54 } \\
& \text { Secondary } \\
& \text { Infection } \\
& \triangle \mathrm{P} 14 \\
& \text { - P15 } \\
& \sim \text { P17 } \\
& \diamond \text { P19 } \\
& \rightarrow \text { P23 } \\
& \rightarrow \quad \mathrm{P} 50 \\
& \text { - P56 } \\
& \text { - P73 }
\end{aligned}
$$

Figure 1. Contribution of plasma IgM to ZIKV neutralization from acute infection through late convalescence. Percent ZIKV neutralization attributable to plasma IgM across ZIKVinfected mothers $(n=10)$ from 8 to 406 days post symptoms (DPS). Each sample tested in three technical replicates. See also Table S1. 
bioRxiv preprint doi: https://doi.org/10.1101/2021.11.23.469700; this version posted November 24, 2021. The copyright holder for this preprint (which was not certified by peer rewipw) is the author/funder, who has granted bioRxiv a licene to display the preprint in perpetuity. It is made
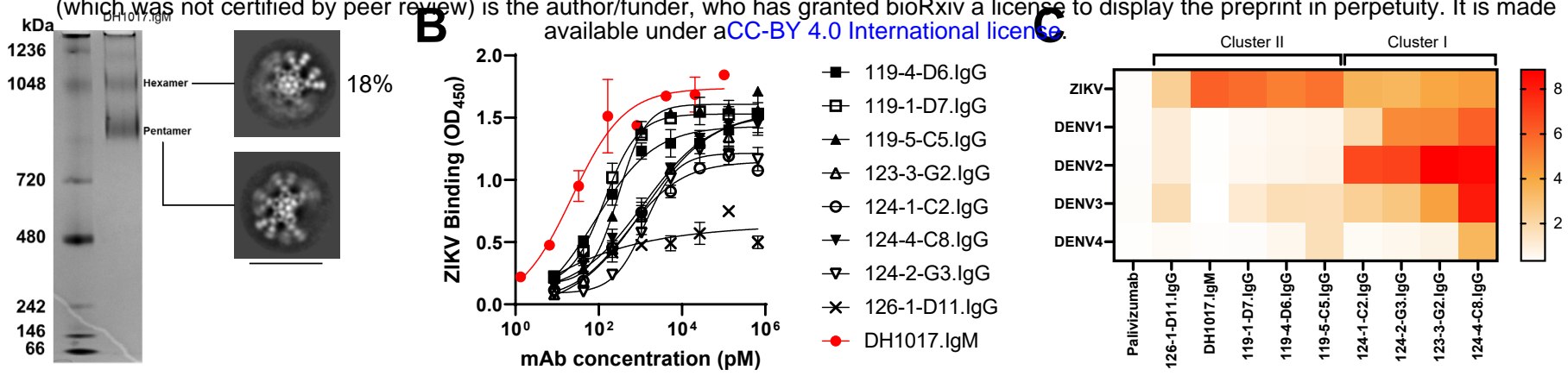

D

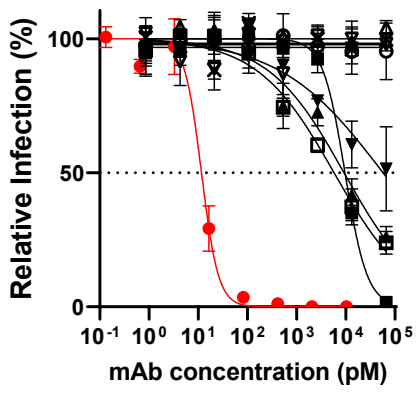

$E$

- 119-4-D6

๑ 119-1-D7

$\leftarrow$ 119-5-C5

$\triangle$ 123-3-G2

- 124-1-C2

$\rightarrow$ 124-4-C8

$\rightarrow$ 124-2-G3

- 126-1-D11

-- DH1017.IgM

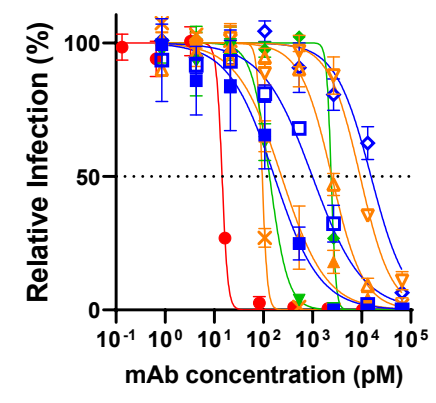

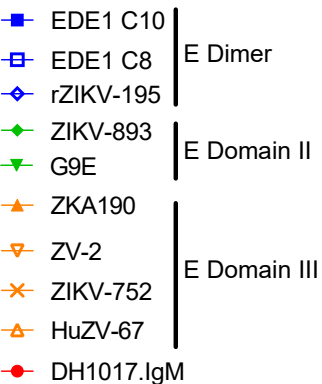

Figure 2. Characterization of B-LCL-derived ZIKV-specific monoclonal antibodies. A. Left: DH1017.lgM native PAGE gel in non-reducing conditions. Bands identified high and low sized molecular species compatible with IgM hexameric and pentameric forms. Ladder on the left. Right: Negative stain electron microscopy of purified DH1017.IgM showing representative class averages of hexameric and pentameric particles. Scale bar is $40 \mathrm{~nm}$. B. Binding to whole ZIKV PRVABC59 virions by $B-L C L-d e r i v e d ~ m A b s ~(n=9)$. $D H 1017 . \operatorname{lgM}$ is shown in red. Error bars indicate standard deviation of two technical replicates. Experiments were independently repeated twice. C. Heatmap showing binding, expressed as LogAUC, to ZIKV and DENV1-4 by the nine B-LCL-derived mAbs. Palivizumab is shown as negative control. Clustering was performed using the Los Alamos Database heatmap tool. D. ZIKV PRVABC59 strain neutralization curves of the 9 B-LCL-derived mAbs expressed as percentage of the number of foci relative to the virus alone condition. Dotted line represents $50 \%$ viral inhibition. DH1017.IgM is shown in the red filled circle. Error bars indicate standard deviation of assays run in triplicate. Experiments were independently repeated twice. $\mathbf{E}$. ZIKV PRVABC59 strain neutralization curves of DH1017.IgM (red) and 9 previously described IgG ZIKV neutralizing antibodies. Colors indicate groups of similar epitopes. Error bars show standard deviation in triplicate measurements. Experiments were independently repeated twice. See also Figure S2. 
bioRxiv preprint doi: https://doi.org/10.1101/2021.11.23.469700; this version posted November 24, 2021. The copyright holder for this preprint (which was not certified byper review) is the author/funder, who has granted bioRxiv a license to display the preprint in perpetuity. It is made
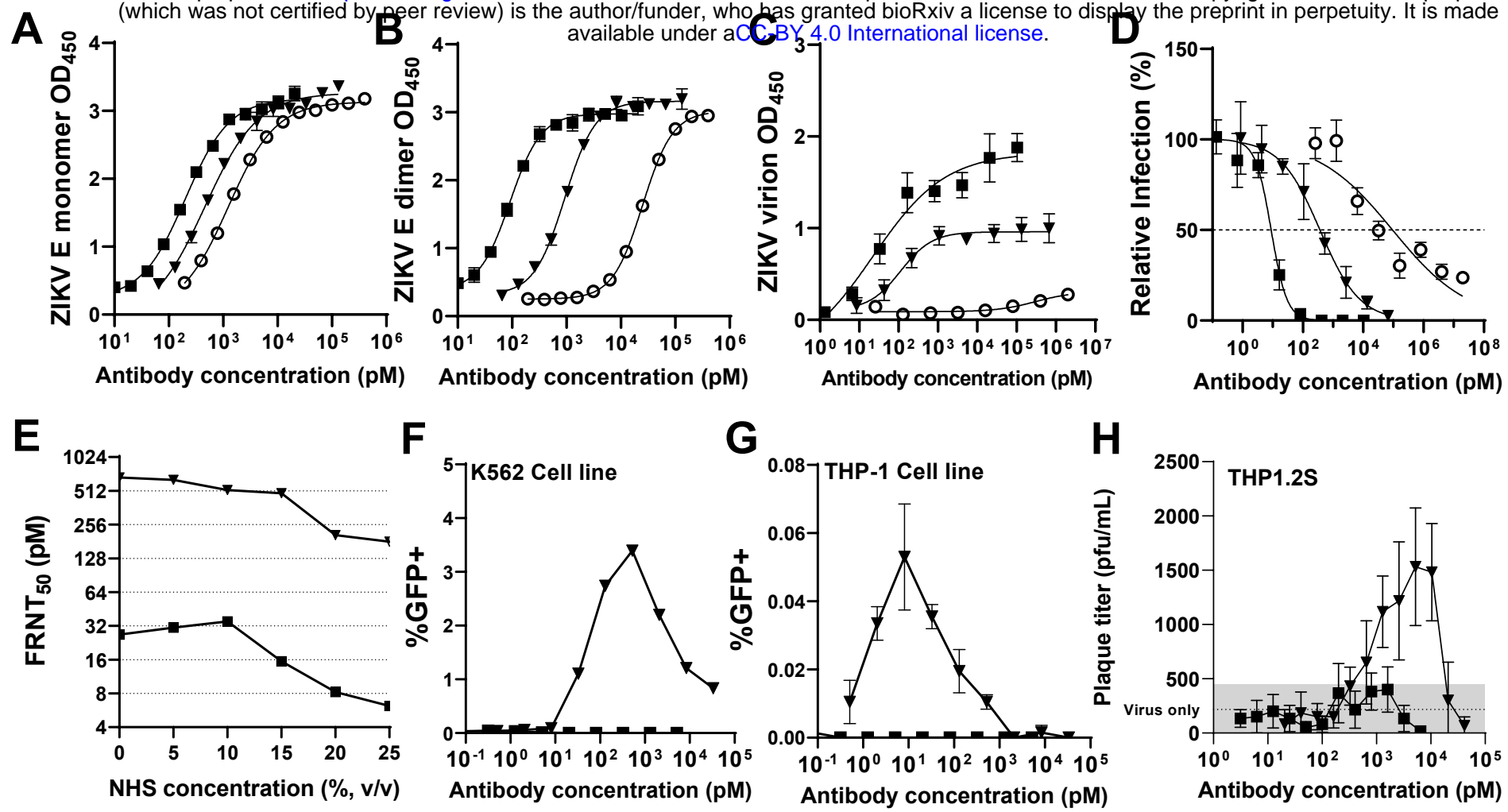

- DH1017.IgM $\rightarrow \mathrm{DH} 1017 . \lg \quad$ - DH1017.Fab

Figure 3. Functional characterization of DH1017.IgM, DH1017.IgG, and DH1017.Fab. A, B. Binding of DH1017.IgM (square), DH1017.lgG (triangle) and DH1017.Fab (circle) mAbs to ZIKV E monomer (A) and dimer (B) measured by ELISA and expressed as optical density at $450 \mathrm{~nm}\left(\mathrm{OD}_{450}\right)$. Error bars indicate standard deviation of duplicate observations. Experiments were independently repeated twice. C. Whole ZIKV virion binding curves of DH1017.IgM, DH1017.IgG, and DH1017.Fab. Error bars show the standard deviation of two experiments, each run with 6-replicates for DH1017.IgM and DH1017.IgG. DH1017.Fab was run in duplicate. D. ZIKV neutralization of serially diluted $\mathrm{mAbs}$. Dotted line denotes $50 \%$ relative infection of $\mathrm{mAb}$ condition as compared to virus alone $\left(\mathrm{FRNT}_{50}\right)$. Error bars indicate standard deviation of mAbs run in triplicate. Experiments were independently repeated twice. E. ZIKV neutralizing titers at $50 \%$ viral inhibition $\left(\mathrm{FRNT}_{50}\right)$ over increasing complement concentrations. Normal human serum (NHS) was used as source of complement at the indicated concentrations $(\mathrm{v} / \mathrm{v})$. Percent infection of the antibody were calculated relative to the virus alone with matched concentrations of NHS. MAbs were run in triplicate. $\mathbf{F}, \mathbf{G}$. Serially diluted $\mathrm{mAbs}$ were incubated with ZIKV H/PF/2013 reporter virus particles and used to infect K562 (F) or THP-1 (G) cells to measure antibody-dependent enhancement (ADE) of infection. Enhancement of infection was scored by GFP expression and measured after 36-48 hours using flow cytometry. Representative ADE data of at least three independent experiments are shown. $\mathbf{H}$. ADE of DH1017.IgM and DH1017.IgG on THP1.2S cells measured by plaque assay. Dotted line shows mean of six virus-only control replicates and the grey area indicates one standard deviation above and below this mean. Representative results from duplicated experiments run with 6-replicates each. Bars show the standard deviation from 6 replicates. See also Figure S3. 
bioRxiv preprint doi: https://doi.org/10.1101/2021.11.23.469700; this version posted November 24,2021 . The copyright holder for this preprint

(which was not certified by peer review) is the author/funder, who has granted bioRxiv a license to display the preprint in perpetuity. It is made available under aCC-BY 4.0 International license.

A
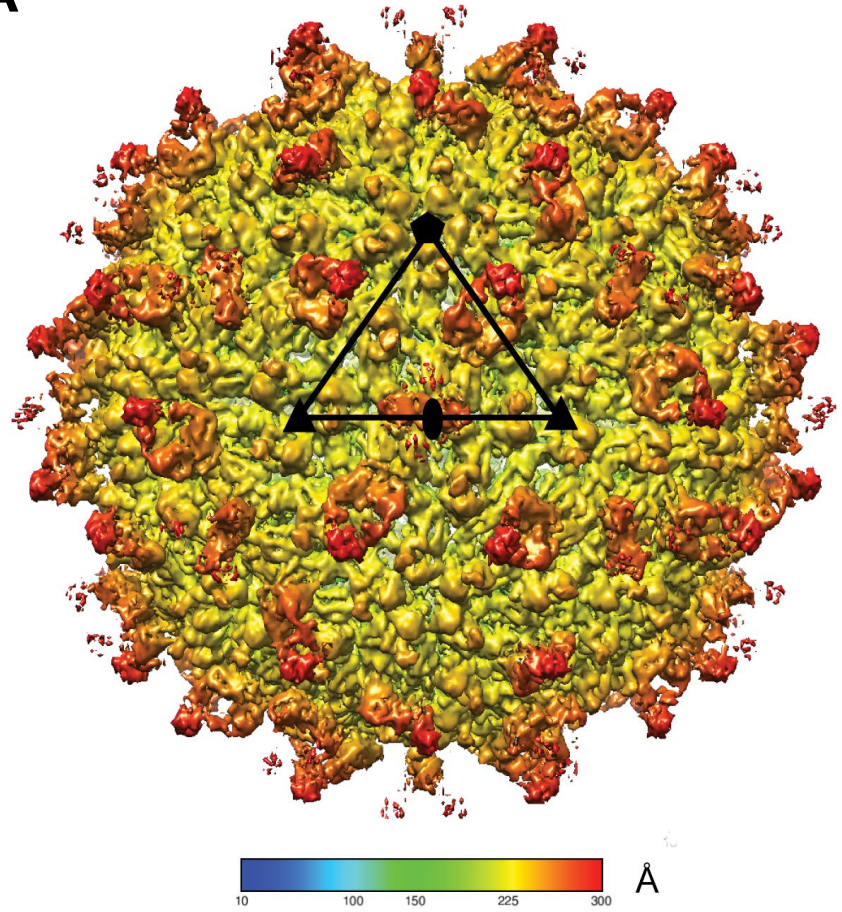

C

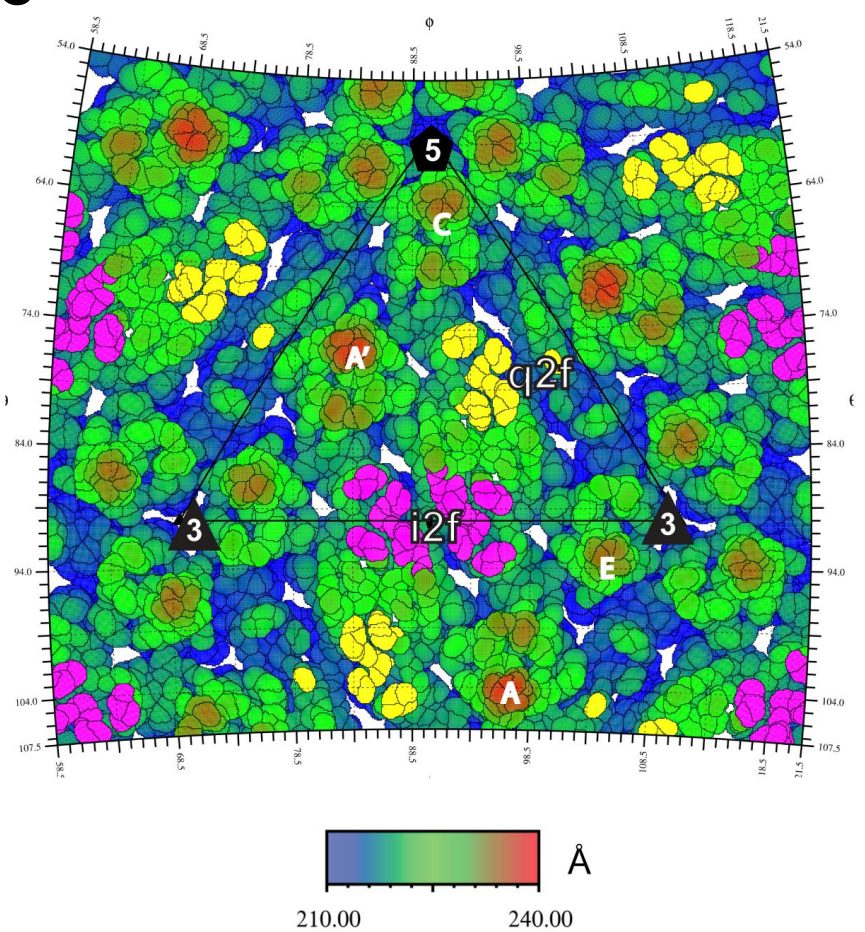

B
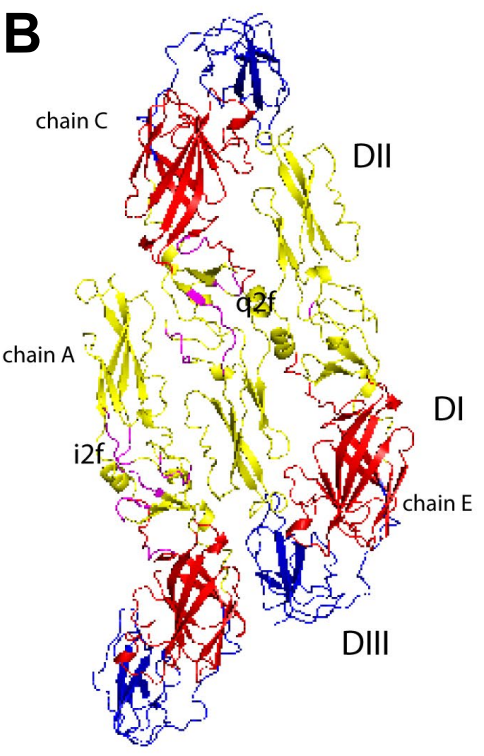
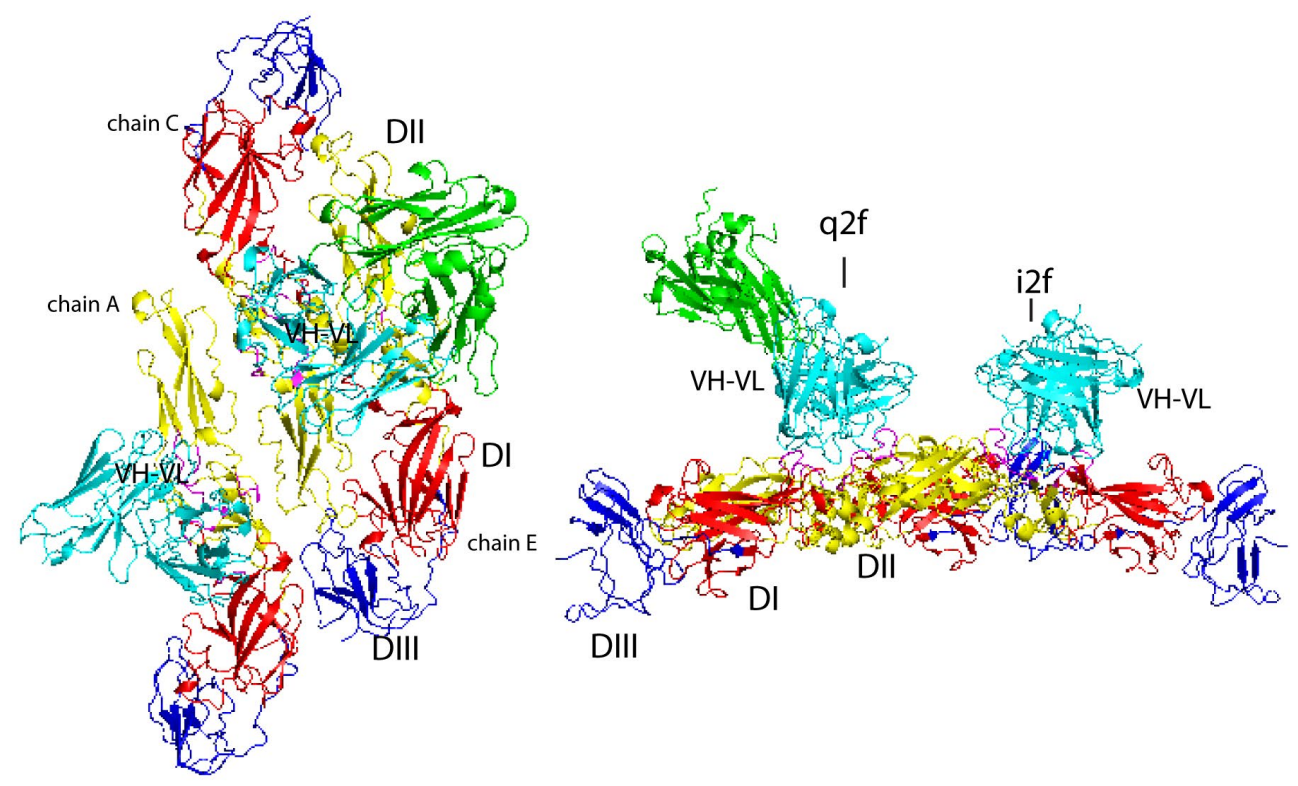

D.

IRCIGVSNRD FVEGM SGGTW VDWEHGGC VTMMAQDKPT VDIELVTTTV SNM AEVRSYC YEASISDMAS DSRCPTQGEA YLDKQSDTQY VCKRTLVDRG 100 WGNGCGLFGK GSLVTCAKFA CSKKIMTGKSI QPENLEYRIM LSVHGSQHSG MIWNDTGHET DENRAKVEIT PNSPRAEATL GGFGSLGLDC EPRTGLFSD 200 LYMTMNNKH WLVHKEWFHD IPLPWHAG AD TGTPHWNNKE ALVEFKDAHA KRQTVMLGS QEGAVHTALAGALEAEMDGA KGRLSSGHLK CRLKMDKLRL 300 KGVSYSLCTAAFTFTKIP AE TLHGTVTVEV QYAGTDGPCK VPAQMAVDM Q TLTPVGRLIT ANPVITESTE NSKMMMLELDP PFGDSYVIG VG 392 

available under aCC-BY 4.0 International license.

Figure 4. DH1017 clone interacts with envelope dimer. A. Surface-shaded view of the Zika virion bound with the DH1017 Fab fragment at a resolution of $5.3 \AA$ acquired via cryo-EM. The color represents the distance to the center and shown by the colored scale bar in $\AA$. The black triangle represents the asymmetric unit, a pentagon represents the five-fold axis, the triangle the three-fold axis, and the oval the two-fold axis. B. Surface representation of the $E$ ectodomain of Zika virus asymmetric unit (PDB 6CO8) shown in top view unbound, then bound with the variable domain of DH1017.Fab (cyan) and the constant domain (green), and a side view of the asymmetric ectodomain bound the DH1017 Fab fragment (left to right). The E ectodomains are colored with DI in red, DII in yellow, and DIII in blue. The residues of the footprint are colored, magenta. See also Fig. S4 and Table S3. C. A radially colored roadmap (scale bar in Å). The icosahedral and quasi two-fold axes are labelled $\mathrm{i} 2 \mathrm{f}$ and $\mathrm{q} 2 \mathrm{f}$, respectively. The monomer chains of two $\mathrm{E}$ dimers are labeled $A^{\prime}$ and $A$ at the $i 2 f$, and chains $C$ and $E$ at the $q 2 f$. Residues on the surface of the virus within $6 \AA$ of the variable domain structure fit to the density map are colored yellow and magenta. Yellow residues are on chain $C$ at the $q 2 f$ axis and magenta residues are at the i2f axis on chain $A^{\prime}$ and A. D. Fab DH1017 epitope shown on the primary sequence of E ectodomain. The epitope residues are colored magenta and the domains DI, DII, and DIII are indicated by line color red, yellow and blue, respectively. 
bioRxiv preprint doi: https://doi.org/10.1101/2021.11.23.469700; this version posted November 24, 2021. The copyright holder for this preprint (which was not certified by peer review) is the author/funder, who has granted bioRxiv a license to display the preprint in perpetuity. It is made

A
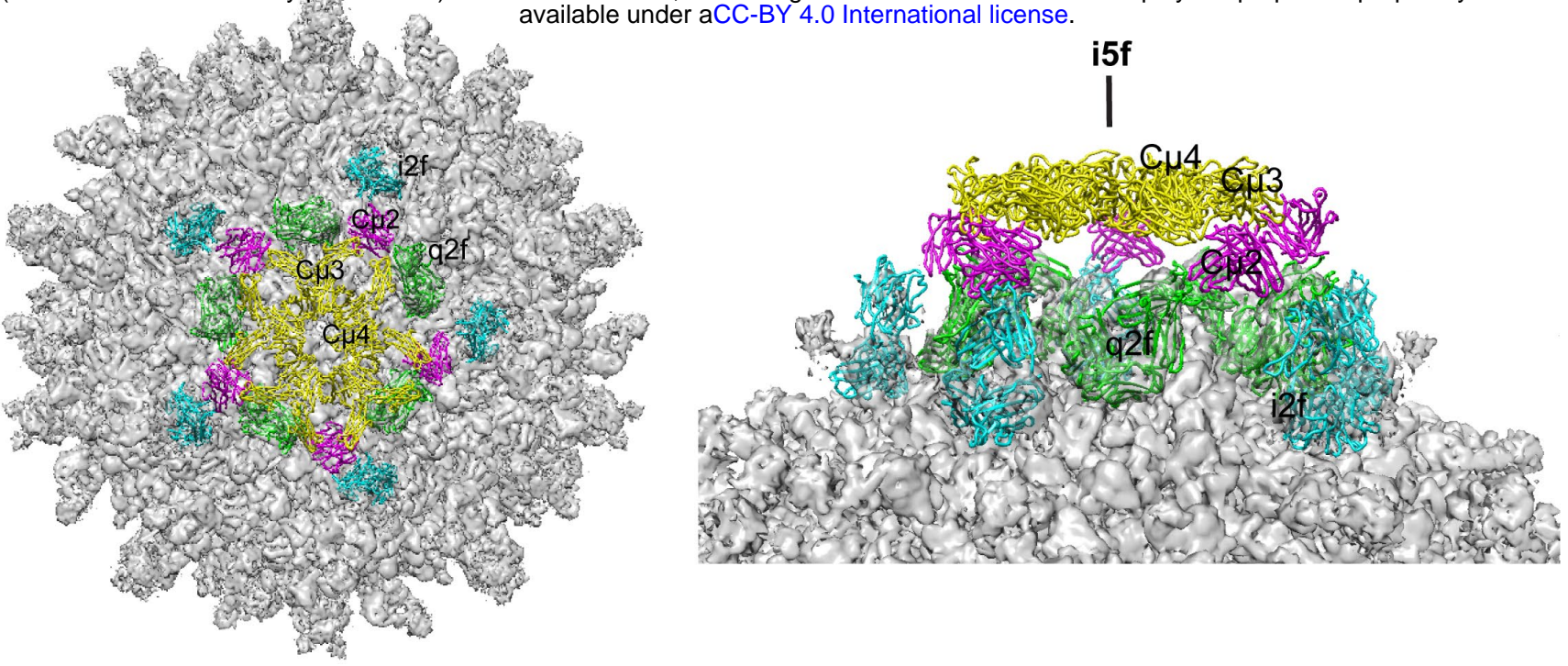

B

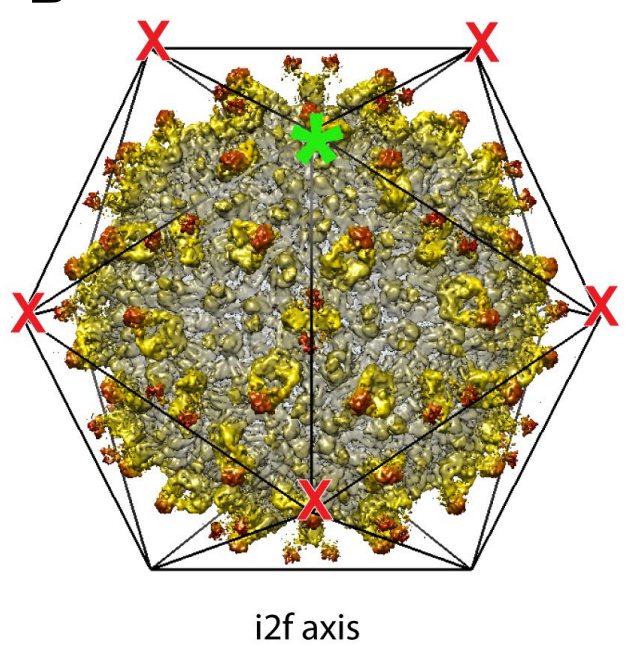

i2f axis
Top down views of virus in icosahedral cage
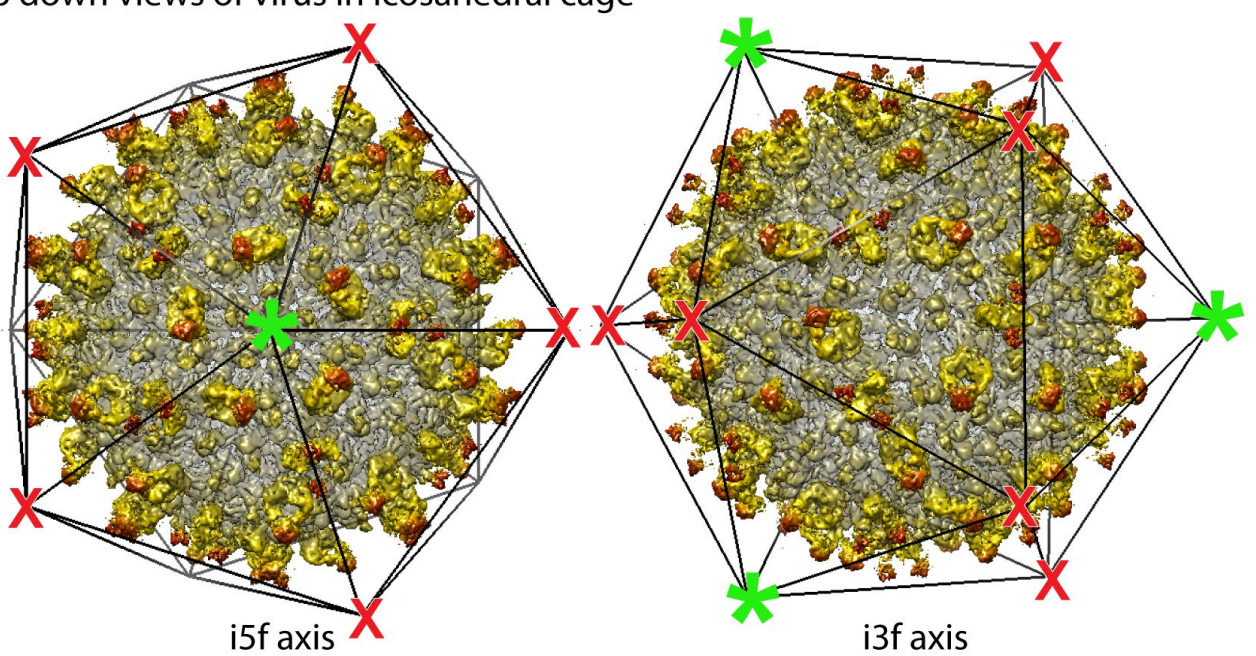

i3f axis

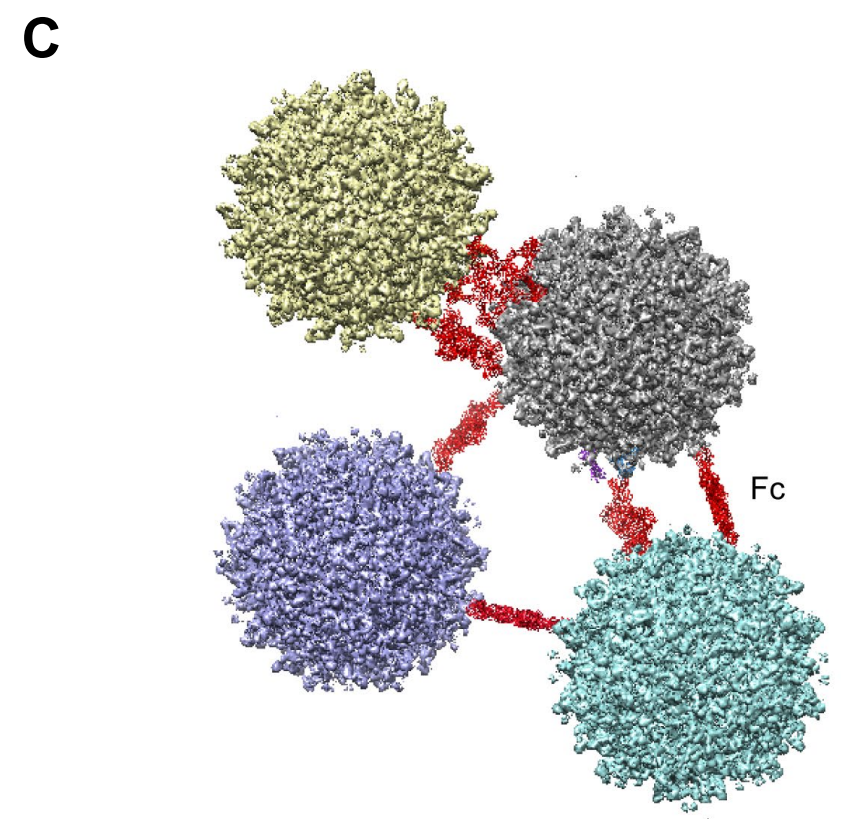




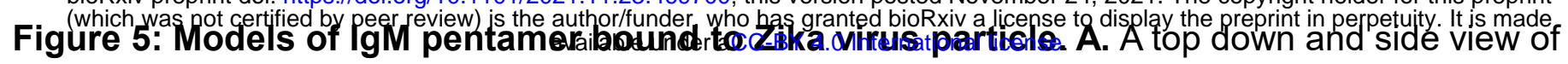
a model of the pentamer binding the Zika virus particle in an umbrella like conformation. The density map is shown in gray. The $\mathrm{Fc}$ domain is shown in yellow, domains $\mathrm{C} \mu 3$ and $\mathrm{C} \mu 4$ are labeled. The $\mathrm{C} \mu 2$ domain is labeled and colored purple. The DH1017 Fab structure is fit to the density map, at the $\mathrm{i} 2 \mathrm{f}$ it is cyan and at the $\mathrm{q} 2 \mathrm{f}$, green. B. The density map of the Fab bound virus particle in an icosahedral cage with top-down views at each icosahedral axis, i2f, i5f, and i3f. The green asterisk indicates a position where the pentamer is bound as in $\mathrm{A}$. The red $\mathrm{X}$ indicates the position of five-fold axes related to the green asterisk by two-fold symmetry that do not have the i2f position available for Fab binding to form the umbrella like conformation. The i $3 f$ view shows positions of complete occupancy for the particle bound as in A. C. Schematic representation of virus particles crosslinked by pentamers. The Fc portion of the molecule is shown in red crosslinking virus. 

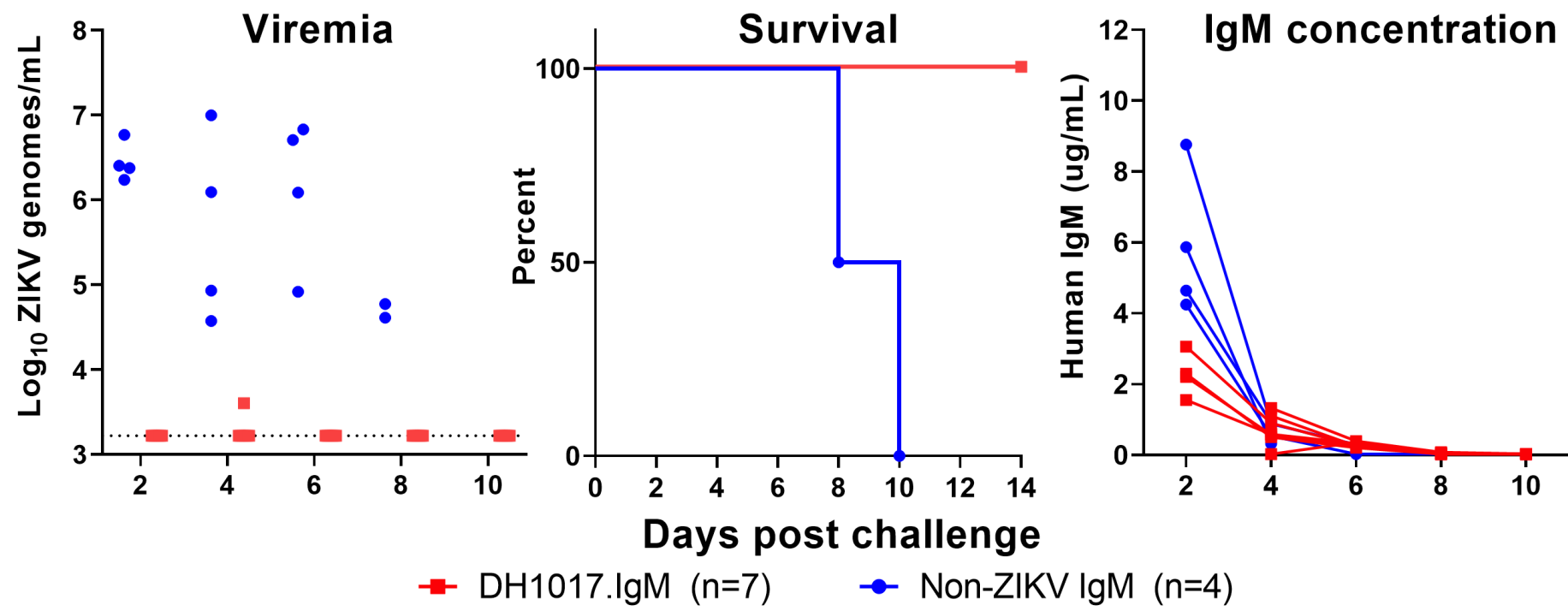

Figure 6: DH1017.IgM protects mice against lethal ZIKV challenge. Five-week-old Ifnar1-/- mice were challenged with 1000 focus forming units (FFU) of ZIKV H/PF/2013 in the footpad on day 0 . At 1 day prior, and 1 day post challenge, mice were intravenously administered $100 \mu \mathrm{g}$ of human IgM monoclonal antibody, either DH1017.IgM ( $n=7)$ or ZIKV non-binding IgM $(n=4)$. Sera was sampled serially up to 14 days post challenge. A. Viral load in serum was assessed by qRT-PCR and limit of detection was 1000 copies $/ \mathrm{mL}$. B. Survival curves for each IgM intervention group. C. Total human IgM concentrations were measured in mouse sera by ELISA over days post challenge. Limit of detection for this assay was $0.08-0.03 \mu \mathrm{g} / \mathrm{mL}$ across assays. 